\title{
'ALWAYS THINK OF THE OBJECTS': EKPHRASIS AS AESTHETICS IN THE CONTEMPORARY NOVEL
}

\author{
by \\ Lucy Eleanor Alston
}

A thesis submitted to Victoria University of Wellington in fulfilment of the requirements of the degree of Master of Arts in English

Literature

Victoria University of Wellington

2014 



\section{Contents}

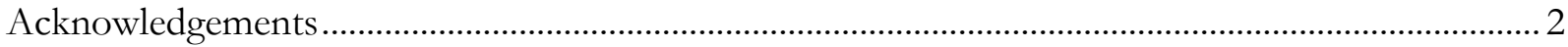

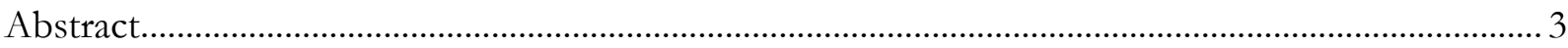

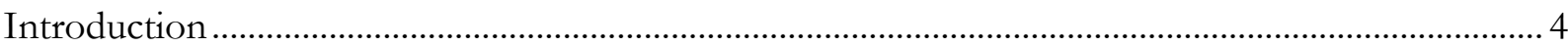

Born Between Mirrors: Leaving the Atocha Station .................................................................................. 11

The Sensuous Presence of the Thing: Infinite Jest .................................................................................. 35

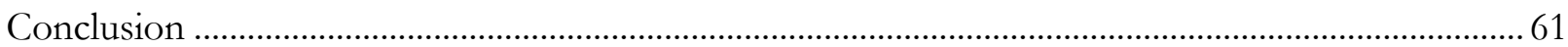

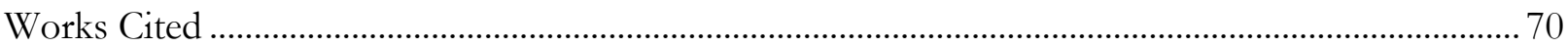




\section{Acknowledgements}

My first thanks go to my supervisor, James Meffan, for providing much-needed guidance, advice, and encouragement throughout the year.

I am also very grateful to Victoria University of Wellington for the award of a Master's by Thesis Scholarship.

Thanks also to my parents, who have always supported me absolutely; Emily Alston, for her constant generosity and advice; Cara Chimirri, for being a wonderful office-mate and friend; and the rest of my family and friends for their support.

Finally to Jason Post, without whom this thesis would not exist: thank you. 


\section{Abstract}

It is a commonplace that ekphrasis - the description in literature of a visual work of art - brings to the fore questions of representation and reference. Such questions are particularly associated with the 'postmodern'; ekphrasis is thus often subsumed under the category of metafiction. There has been little critical attention, however, to how the ekphrastic mode might be understood in aesthetic terms. This thesis considers the nature of ekphrasis's referential capacity, but expands on this to suggest a number of ways in which the ekphrastic mode evinces the aesthetic and ontological assumptions upon which a text is predicated.

Two case studies illustrate how the ekphrastic mode can be figured to different effect. In comparing these two novels, this thesis argues that the ekphrastic mode makes clear the particular subject-object relations expressed by each. If Lukács is correct in asserting that the novel mode expresses a discrepancy between 'the conventionality of the objective world and the interiority of the subjective one', ekphrasis provides a fruitful but under-explored avenue for critical inquiry because, as a mode, it is situated at the point at which subject and object must converge.

The first chapter of this thesis is concerned with Ben Lerner's Leaving the Atocha Station (2011), a novel that includes both traditional ekphrastic descriptions and embedded photographs and references to critical theory that function ekphrastically. David Foster Wallace's Infinite Jest (1996) provides a contrast: the novel makes continued reference to film - a medium defined by its temporal qualities - but as used in the novel the ekphrastic mode implies a fixed, ahistorical schema. The implications that such differences have on the novel mode and critical discourse are explored in the final section of the thesis. 


\section{Introduction}

But your eyes proclaim

That everything is surface. The surface is what's there And nothing can exist except what's there.

- John Ashbery, "Self-Portrait in a Convex Mirror"

Ashbery's "Self-Portrait" is perhaps one of the most well-known examples of the ekphrastic mode - the description in literature of a visual work of art. The poem is also peculiar in Ashbery's oeuvre: unlike much of his other work, it is a poem very much about the poet's personal experience. The pronouns here still shift in the characteristic Ashbery way, but this is clearly a poem about a particular encounter with a particular artwork: when the speaker states 'I saw it with Pierre in the summer of 1959', there is no doubt as to the specificity of the subjectobject encounter being described (Ashbery 75). This combination of ekphrasis and particularity makes sense; if the poem is exceptional, it is because ekphrasis expresses the response to and reception of the art object, and is thus inescapably focused on the subjective, phenomenological experience of its apprehension.

"Self-Portrait" might seem a peculiar starting point for a thesis focused on novelistic ekphrasis. Yet Ashbery's poem is significant here because - in addition to the neat coincidence that both authors under discussion have quoted from it - it is the poem of Ashbery's which, in Ben Lerner's words, 'doubts his poetry' (Lerner Ashbery 212). ${ }^{1}$ In other words, it is a poem that uses the ekphrastic mode to express the limitations of the poem as a form. The 'movement / Out of the dream into its codification' is the movement from the vision of an art that can successfully capture a singular moment of experience to an art that is insufficient at rendering experience at all (Ashbery 73). "Self-Portrait" is therefore something of a paradox: it expresses the limitations of poetry through poetic form. In this thesis I want to suggest that the ekphrastic mode is particularly suited to this task: the convergence of subject and object required in the description

\footnotetext{
1 The same quote from "Self-Portrait" appears in Leaving the Atocha Station (Lerner 146) and in Wallace's short story "Little Expressionless Animals" in the collection Girl with Curious Hair (42).
} 
of an artwork immediately brings to the surface questions of representation, aesthetics, and the possibility of a relationship between text and world.

This thesis will analyse the ekphrastic moments and embedded art objects in the novels Infinite Jest, by David Foster Wallace, and Leaving the Atocha Station, by Ben Lerner. This will form the basis for a broader argument about the texts and the subject-object relations they describe. The particular nature of ekphrasis means that it highlights both the ontological and the aesthetic assumptions on which a fictional text is based; what the concept offers as a framework for inquiry, then, is a way in which to analyse both these aspects of a novel while remaining focused on the particular form of the novel itself. In this sense, in addition to analysing each text, I want to provide an example of how the ekphrastic mode is a productive object of inquiry in and of itself; though often subsumed under the idea of metafiction or self-reference - and therefore the 'postmodern' as a general category - the ekphrastic mode has a far richer and more varied critical history, and it can express far more in a text than simple reflexivity.

This is not to suggest, however, that the choice of texts here is arbitrary. The fact that ekphrasis occurs in each novel evinces their common concerns; equally, because each novel employs the mode to such different effect, the gap between them provides the necessary space for critical inquiry. While both novels can be broadly classified as 'contemporary', the generation that elapsed between their writing is not irrelevant. It would be too easy to suggest that each is wholly representative of its time, but both novels are certainly products of their specific historical moments (although the narrative present of Infinite Jest is actually later than that of Leaving the Atocha Station). This is key: the major feature they have in common is a concern with their own possibility. If the novel is, as Lukács states, the product of a division between 'the conventionality of the objective world and the interiority of the subjective one', the novel is therefore relegated to the position of reinforcing this division, thus rendering itself superfluous (Lukács Novel 70). In approaching these texts, my aim is therefore neither to pit them against one another in order to declare one or the other the winner, nor to sublate their considerable differences in service of a productive synthesis. Instead, using the concept of ekphrasis as organising principle, I want to outline what it is that each text expresses of its own relation to the world in both form and content, and to consider whether this expression is internally coherent and consistent.

It is important at this point to define to what, exactly, the term 'ekphrasis' will refer. This is more necessary than it might seem: while the term originates in ancient Greek, it has been subject to various critical definitions throughout history. James Heffernan defines it - in 
accordance with its most common usage - as the 'verbal representation of a visual representation' (Heffernan 3). The most famous example of ekphrasis, Homer's description of the shield of Achilles, falls into this category, but there are narrower definitions which specify that - as in Homer, or Keats's "Ode on a Grecian Urn" - the verbal response must come in the form of poetry, while the art object must be static and physical - a shield, or a vase. Such a strict definition seems unhelpful; the nature of ekphrasis means that it very often describes art objects that - like Achilles' shield or Keats' vase - do not actually exist. This lack of corporeal, non-textual presence seems to make redundant any definition of ekphrasis that reduces its application only to painting, sculpture or the objet d'art, the physical presence and stasis of such objects is illusory anyway. In more recent work on the subject, the term ekphrasis has been applied to an expanded field of referents. Siglind Bruhn suggests in his Musical Ekphrasis - as might be inferred from his book's title - a broader conception of ekphrastic objects, and, further, that the representation itself need not even be verbal; instead, the important element is that of 'transmedialization' (Bruhn 51). This latter point, while interesting, places it outside the scope of a thesis focusing on literary texts; all the ekphrases I will discuss here are necessarily verbal representations. What is useful about Bruhn's idea of transmedialization, however, is that it radically expands the possibilities of the term, allowing it to be applied to a broad range of subject-object encounters. Particularly relevant here is the inclusion of cinema: both novels contain ekphrastic descriptions of cinematic objects that will be discussed later in this thesis.

In Ekphrasis: The Illusion of the Natural Sign, Murray Krieger puts the term to further work, suggesting that rather than simply a term of poetic description, ekphrasis can be understood as evincing a general principle of literary representation. Krieger refers to the term's classical use as meaning a 'verbal description of something, almost anything, in life or art', extrapolating from this to suggest that ekphrasis offers a 'device to interrupt the temporality of discourse, to freeze it during its indulgence in spatial exploration' (Krieger 7). Krieger maintains that a distinction between what he calls 'natural' signs that act as a 'visual substitute' for their object of reference, and the arbitrary sign system of language is untenable; in focusing on the temporal elements of ekphrasis, Krieger argues that the mode offers the most 'extreme and telling' example of the spatial potential of the literary text (Krieger 2-6; 12). This concept - that the literary text is itself an object with a physical presence in the world - is explored by both Lerner and Wallace.

While the extant critical work on ekphrasis greatly informs my argument here, I want also to depart from accounts such as Krieger's by bringing ekphrasis into a dialogue with aesthetic theory. Despite the pressure put on questions of aesthetics through the inclusion of the ekphrastic mode or the embedded art object, there has, to my knowledge, been a lack of critical 
attention to how such inclusions might function outside of the question of reference. In other words, the commonplace readings of ekphrasis as either a historical category, or as characteristic of postmodern reflexivity mean that its particular qualities as a mode of expression have been ignored. For this reason, I want here to look at examples of the ekphrastic mode in relation to an aesthetic tradition that is itself concerned with the relation of text to world. This question is the central organising principle for many of the developments in late-twentieth and earlytwenty-first century literature; as Peter Bürger argues, the reintegration of art and the praxis of life is what distinguishes the historical avant-garde. Ekphrasis is a fertile point from which to approach these questions because it is situated, conceptually speaking, at the intersection at which the object is perceived and translated into thought.

Ekphrasis also acts as a useful organising principle for this discussion because unlike, say, the embedded novel or author figure, the difference in medium makes it somewhat easier to move away from questions of reference that focus only on text. It is also important to clarify, here, that in this thesis the concept of the mise en abyme - the artwork within an artwork - is not interchangeable with the ekphrastic mode. While the mise en abyme suggests an embedded artwork that through its content sheds light on the content of the framing narrative, ekphrasis instead attends to the artwork's response and reception. In other words, while the mise en abyme might reflect thematic elements (the classic example here is Hamlet's embedded play), ekphrasis emphasises the process of reading itself. Similarly, recent work such as Benjamin Widiss's Obscure Invitations exemplifies the problem with an approach focused on the author figure: Widiss examines a number of twentieth-century texts which include author figures, concluding with an affirmation of intentionality that seems unavoidable given his subject matter. On the other hand, critics such as Mark Currie approach 'postmodern' fiction with the view that its self-awareness, as evinced by inclusions such as authorial stand-ins, or art objects, aims to render the analysis of the critic 'redundant in advance' (Currie 155). Currie is useful in acknowledging - unlike Widiss - the complexity of intentionality; though his conclusions are comparatively pessimistic, he also gestures towards a criticism based not on exegesis (because this has been anticipated in the text itself) but on reading against the implied author. In moving the critical conversation from conventional understandings of metafiction to ekphrasis and embedded art objects, I hope to avoid both a return to authorial intention and the emphasis of authorial unreliability - to which both the authorial stand-in and mise en abyme devices necessarily lead - and to thus avoid the associated critical aporia that Currie anticipates. Similarly, I want also to dispel here the idea that ontological 'levels' exist within a text; I begin from the understanding that the text is itself a physical and conceptual object and that those 'objects' 
referred to textually exist at the same level as the text itself; that is, there is no essential difference between media in terms of representational adequacy. Ekphrasis offers no 'object' whether real or fictional - except the text. The question of representational adequacy is therefore somewhat redundant: there is nothing to represent. Instead, it is the process of representation - how the ekphrastic mode figures the art object - that is of value here.

In addition to perhaps augmenting the current critical status of ekphrasis, I want also to comment on the criticism of both Lerner and Wallace. Criticism of the latter has expanded enormously in recent years, in both amount and methodology. ${ }^{2}$ Since Wallace's death, there has also been an increase in non-academic publications by or about him. ${ }^{3}$ The rapid generation of something approaching a cottage industry surrounding Wallace means that a diverse range of critical lenses have been applied to his work, with varying degrees of success. Some recent criticism has taken into account the novel's engagement with critical theory: Martin Paul Eve, notably, reads Infinite Jest and The Pale King alongside Thomas Pynchon and in light of the concept of 'metamodernism', a term coined by Timotheus Vermeulen and Robin van den Akker in their essay "Notes on Metamodernism". Eve takes issue with certain aspects of Vermeulen and Akker's text - particularly their reading of Kant - but concludes that the term 'metamodernism'

does hold value, not as a generic classification, but as a set of tropes that identify regulative utopianism through the dialectical image of a sincerity infused with naivety and undermined by scepticism. This specific constellation could be called the 'metamodern aspect' of a text. Metamodernism as a reading practice offers a means of excavating the latent ethical connotations of supposedly nihilistic postmodern texts, it is a tool for rethinking the millennial turning point for a new literary ethics. (Eve 22)

While Eve's use of the term 'excavating' here seems to conform to that critical mode Currie dismisses, his argument is useful in that it suggests a way of looking at Wallace that is informed by his own discussion of ethics without being circumscribed by them. While Wallace's work is indubitably concerned with ethical questions, there is a tendency to look at such concerns through the lens of Wallace's own words on the matter - the latter being increasingly readily

\footnotetext{
2 The conception and expansion of the field of 'Wallace studies' is itself a topic worthy of investigation; such a study, while interesting, is not relevant to my purpose here. See, for example, the recently published Consider David Foster Wallace, a somewhat patchy collection of essays described by the editor, David Hering, as marking the 'commencement' of 'Wallace studies' (Hering 9). Included are essays on a diverse range of topics: Fredric Jameson, geometry, the New Sincerity. Yet the major problem with this - and much other Wallace criticism - is what Stephen Burn (himself author of a number of books on Wallace) describes as 'a tone more suited to the proselytizing of fundamentalist religion than literary criticism' (Burn Consider 467). For a less problematic collection of essays on Wallace, see The Legacy of David Foster Wallace (2012).

3 See, for example: Wallace's unfinished novel, The Pale King (2011); the essay collection Both Flesh and Not (2012); the print publication of the Kenyon commencement address (previously available for free online) as This is Water (2009); a biography, D.T. Max's Every Love Story is a Ghost Story (2012); Stephen Burn's collection Conversations with David Foster Wallace (2012); a book of poetry and collage, Bough Down (2013), by Karen Green (Wallace's widow); and the title essay of Jonathan Franzen's collection Farther Away (2012).
} 
available. ${ }^{4}$ Eve instead chooses to take seriously Wallace's conception of ethics though finds it ultimately lacking in Infinite Jest because the novel oscillates (a characteristic of 'metamodernism') between realism and experimentation, emotional empathy and 'metaspeculation' (Eve 22).

Extant criticism on Leaving the Atocha Station is, in contrast, practically non-existent. ${ }^{5}$ This is undoubtedly due in part to Lerner's relative contemporaneity; Infinite Jest's date of publication gives it a full fifteen year head-start in this regard. But there are other considerations, too: Lerner's novel (my focus here, though his poetry - mostly published before Leaving the Atocha Station - is equally bereft of critical attention) is - perhaps to an even greater extent than Infinite Jest - surely the kind of text Currie has in mind when he discusses those textual devices designed to 'anticipate' their own criticism. To suggest that fiction which is engaged with philosophical or theoretical ideas is a new development would of course be ridiculous, but novels such as Infinite Jest and Leaving the Atocha Station pose a particular problem for literary study because they engage with criticism that directly relates to the situation of the novel in the world. Both novels refer to critical theory - in quite different ways, as we will see - explicitly within the text, but more importantly, in both novels form and content are informed by critical praxis. From a critical standpoint, then, while the lack of attention given to Lerner makes his work a fertile ground for inquiry, it also brings to the fore the question of what position might be available to the critic without following the critical voice of the text itself, or simply confirming this voice through presenting a reading in opposition to it.

While the resonances between Infinite Jest and Leaving the Atocha Station are many, this thesis is for the most part not strictly comparative. In the first chapter I look at Lerner's novel; in the second, Wallace's. The nature of my argument in each chapter has dictated that their form remain continuous. Ekphrasis provides the point of entry for each novel, but its function in both novels creates a problem which I try to use critical theory to resolve, or at least to clarify. Hence this thesis incorporates the work of theorists themselves concerned with the relationship between subject, text and world - in particular György Lukács, Walter Benjamin, Theodor

\footnotetext{
${ }^{4}$ The ur-text for Wallace on ethical fiction is almost certainly his "E Unibus Pluram" essay and the interview with which it was originally published. Other oft-quoted sources are his Kenyon commencement address, now published as This is Water, and the book-length interview with David Lipsky, Although Of Course You End Up Becoming Yourself.

5 At the time of writing there is - to my knowledge - no published academic work on Lerner. Leaving the Atocha Station was, however, widely reviewed, prominent examples being James Wood in the New Yorker (discussed below, and republished in his essay collection The Fun Stuff) and Lorin Stein in The New York. Review of Books. The latter is of some interest as it is the only example outside of this thesis in which Infinite Jest and Leaving the Atocha Station are brought into dialogue; Stein writes: 'Since David Foster Wallace's Infinite Jest, it has been one task of the realist novel to describe or at least acknowledge the portion of our lives spent looking at a screen' (Stein n.p.).
} 
Adorno and Gilles Deleuze - in order to further understand the ontological and aesthetic relations expressed in each novel. 


\section{Born Between Mirrors: Leaving the Atocha Station}

In perhaps the most prominent review of Ben Lerner's Leaving the Atocha Station, the critic James Wood describes the novel's central thesis thus: 'it is one of the paradoxes of this cunning book that what might seem a skeptically postmodern comedy is also an earnestly old-fashioned seeker of the real'. Wood identifies an important element of the novel, but the word 'real' here is perhaps misleading; certainly, Lerner's novel is concerned with the relationship between what the narrator, Adam Gordon, calls the 'actual' and 'virtual', yet this relationship is predicated not on the final triumph of either one category, but on the thoroughly dialectical character of their interaction. ${ }^{6}$ In this chapter I want to suggest that on reading the novel, it becomes clear that any distinction between 'actual' and 'virtual' is impossible to maintain, as demonstrated through the treatment of, and discourse around, the art object.

The art object's significance is made apparent in the first few pages of the novel. After a short description of his morning routine, Adam visits the Museo del Prado, where he likes to stand daily in front of Rogier van der Weyden's The Descent from the Cross. What is interesting, here, is the ease with which Adam slips into the ekphrastic mode: 'Mary is forever falling to the ground in a faint; the blues of her robe are unsurpassed in Flemish painting' (Lerner Atocha 8). This contemplative insight is juxtaposed with what follows, as Adam appears to quote directly from the painting's accompanying placard: 'C.1435; 220 X $262 \mathrm{~cm}$. Oil on oak panelling' (8). While the former sentence fits squarely into the mode of ekphrastic, aesthetic contemplation - the 'forever falling', with its suggestion of pathos; an awareness of the work's place within the canon - the latter confuses this assumption: are we privy to Adam's own experience (and knowledge) of the artwork, or is the whole section simply a quote from the work's wall-text?

In the paragraphs that follow, it seems we receive an answer: Adam observes a man who, upon viewing the van der Weyden, '[breaks] suddenly into tears', and whom he begins to follow around a few rooms of the Prado (8). Adam's interest is piqued because he wonders whether

${ }^{6}$ Lerner also uses the terms outside of the novel: see "The Actual World" (2013). 
the man is having what he calls 'a profound experience of art, something of which he believes himself incapable (8). This self-reflection appears to clarify the earlier disjunction between artwork, response, and mediation: if Adam feels a 'disconnect between [the] experience of actual artworks and the claims made on their behalf, as he states, then what may have seemed to be an example of the ekphrastic mode is shown, in retrospect, to be an example only of this 'disconnect' (9). The insights that Adam seemed to be producing himself may be understood as simply reproductions of the already-said; the language of art history and the discourse of art appreciation are repeated by Adam in place of any 'profound' experience of his own. The ekphrastic encounter is conventionally predicated on the art object being directly present to the speaker in order to create the necessary phenomenological encounter, yet here the presence of the van der Weyden does not prompt the subject's contemplation as expected. This reading, however, ignores another statement Adam makes about the painting. His daily routine altered by the weeping man's presence, Adam considers whether to view another work as substitute but concludes that he is 'too accustomed to the painting's dimensions and blues' to do so (8). In other words, while Adam can identify the 'disconnect' between his expectations of the artwork and the encounter that actually occurs, he is also - perhaps unconsciously - attentive to the art object's specific physicality and presence in the material world. This complicates the idea of a binary in which access to the 'real' is possible: attention to the art objects within the novel reveals a schema that is far more equivocal.

Adam's response to the painting makes clear that ekphrasis - especially in a contemporary context - is a mode fraught with ontological problems. In his Picture Theory, W.J.T. Mitchell describes the three 'phases' of the relationship between criticism and ekphrasis: the first, 'ekphrastic indifference' is the neutral belief that the verbal and visual cannot be commensurate, because a verbal representation 'cannot represent - that is, make present - its object in the same way a visual representation can' (Mitchell 152). This then leads to 'ekphrastic hope', the point at which 'the impossibility of ekphrasis is overcome in imagination or metaphor'; ekphrasis here becomes paradigmatic of linguistic expression's own tendency towards the aesthetic, of 'the shaping of language into formal patterns that "still" the movement of linguistic temporality into a spatial, formal array' (Mitchell 153-4). This second kind of ekphrasis is clearly influenced by Krieger's work; as Mitchell states, it is the point at which ekphrasis seems 'paradigmatic of a fundamental tendency in all linguistic expression' (Mitchell 152). This 'utopian' claim is contrasted with 'ekphrastic fear': as the boundary between the verbal and visual seems prone to collapsing, there comes the 'moment in aesthetics when the difference between verbal and visual mediation becomes a moral, aesthetic imperative rather than (as in the first "indifferent" 
phase of ekphrasis) a natural fact that can be relied on' (Mitchell 154). Mitchell's categories are useful in themselves when identifying how ekphrasis is figured in a particular text, but Mitchell also argues that the multitude of possible perspectives on ekphrasis suggests an ambivalence that is one of the principal themes of ekphrasis itself; it must 'work through' the 'problems staged for it by the theoretical and metaphysical assumptions about media, the senses and representation' (Mitchell 163-4). In addition to being 'about' the art object, then, the ekphrastic mode also entails a consideration of its response and implications.

In Leaving the Atocha Station, the problems Mitchell finds in giving a totalising account of the ekphrastic mode are clearly evident. The implied binary between 'actual' art object and 'virtual' text is immediately complicated by the inclusion of verbal representations of the visual. Yet as Mitchell states, as a mode ekphrastic poetry or prose is no different from other descriptive or narrative discourse; grammatically speaking, '[e]kphrastic poems speak to, for, or about works of visual art in the way that texts in general speak about anything else' (Mitchell 159). The problem of ekphrasis therefore comes from common assumptions about individual media: the visual arts, for example, are thought to be inherently spatial, while the verbal is in some sense abstract and characterised by non-corporeal objects: narratives, ideas, arguments. Such categorisation is of course reductive - 'paintings can tell stories, make arguments, and signify abstract ideas: words can describe or embody static, spatial states of affairs' - yet these assumptions show that the confusion of ekphrasis is not predicated on any essential semantic difference between media (Mitchell 160). Instead, Mitchell argues, the metaphor that the 'the medium is the message' has become axiomatic and has thus eclipsed the common relation all media have to their referents. Practical differences between media are therefore converted into 'metaphysical oppositions which seem to control our communicative acts, and which then have to be overcome with utopian fantasies like ekphrasis' (Mitchell 161). In the case of Leaving the Atocha Station, the perception of an opposition between visual and verbal is similarly the result of certain assumptions about media rather than variations in the capacity for representational adequacy. Adam fails to convert his experience of the artwork into ekphrastic contemplation not because of a difference between the ability of different media to translate the object, but because, despite the painting's physical presence, it remains phenomenologically distant and unable to be experienced at all.

Representational adequacy is therefore not the most pressing question prompted by the art objects and ekphrastic passages in Lerner's novel. Much of the problem and confusion of ekphrasis, in Mitchell's account, lies in locating the art object's situation within a given semiotic 
system; a system which, as Mitchell points out, quite clearly does not differentiate between individual media, form or content. The question of representation is often posed with regard to ekphrastic objects that are themselves representative: many of the most oft-cited historical examples of ekphrasis fall into this group, from Homer's Shield of Achilles passage in the Iliad, through Keats's urn, to Auden's “Musée des Beaux Arts”. Such ekphrastic moments seek - as Mitchell describes - to make present the absent art object, through representation: that is, through describing a description. This raises the question, however, as to how the ekphrastic encounter might function when the art object is itself focused on its own objecthood: an art object that is not figurative or even 'abstract' in the conventional sense (as this still seems to imply some degree of representation) but performative, theatrical, projecting towards the spectator (as per Michael Fried) rather than towards a final referent would surely create a problem in the conventional understanding of ekphrasis. Such art objects might point towards questions not of reference but of experience; attention to ekphrasis must therefore involve attention to both the referential capacity and the phenomenal - the spatial and haptic aspects, and the experience of the object in time - of any given encounter with the art object.

In addition to the ekphrastic mode - or some approximation of it - the first section of Leaving the Atocha Station introduces another recurring device which similarly questions the easy equation of verbal and virtual, visual and actual. There are five photographs in the novel, each captioned with a quote from the body text, though these captions are never from the pages directly surrounding the photograph itself. The photographs are, however, generally linked with the point at which they intercept the narrative discourse: on page 11 there is a detail from van der Weyden's The Descent from the Cross, just after the section in the Museo del Prado concludes; on page 103, a photograph of the Alhambra interrupts the discourse at the point where Adam returns from Granada with his quasi-girlfriend Isabel, wondering if he 'would be the only American in history who had visited Granada without seeing the Alhambra' (99). While they are linked to story events, the photographs do not necessarily serve an illustrative purpose; the knowledge of what the Alhambra looks like does not reveal anything further about the narrative itself. The detail of the van der Weyden might, one could argue, in some sense 'illustrate' - it is a visual representation of an object previously described in the discourse - yet this illustrative purpose is undermined by it being only a detail - and a grayscale one at that - of a work whose very importance to Adam is predicated on its 'dimensions' and 'blues'.

Recourse to the captions, then, seems necessary; as Walter Benjamin states in "The Work of Art in the Age of Mechanical Reproduction", the caption's function is imperative in relation to the 
photograph, as the caption comes to dictate the final signified itself (Benjamin 226). Unlike the relation of title to painting, Benjamin argues, the nature of the photographic caption is that of an 'explicit' signpost towards a referential telos - in the newspapers to which Benjamin is primarily referring, the meaning of a particular photograph is drastically altered by its caption (Benjamin 226). In the case of Leaving the Atocha Station, then, we might expect the caption to contextualise the photograph and link it to its surrounding text, allowing us to understand what exactly the photographs are illustrating. Yet in the novel the caption is not commensurate with the photograph: the captions do not allow the image to be contextualised or situated within a context of stable meaning. Instead, they do the exact opposite, taking images whose placement in the text makes sense even if their purpose remains unclear and destabilising them through reference to disparate textual events.

The foregrounding of this incommensurability, or rather non-commensurability, is most evident in the photograph of Francisco Franco that appears towards the end of the novel (141). References to Franco can be found throughout the text, as Adam's stated purpose in Madrid is to write a 'long, research-driven poem' on the literary legacy of the Spanish Civil War (23). The photograph depicts Franco as seen from below, speaking at a podium with his face obscured. Underneath is the caption: "The proper names of leaders are distractions from concrete economic modes", a quote that comes from Adam himself, when, in an earlier conversation with Isabel, he tries 'to sound deep, hoping concrete and mode were cognates' (50). Initially, then, photograph and caption seem complementary: Franco's face is not visible, therefore his specific identity is obscured; thus, the photograph could quite easily be read as a visual parallel to Adam's statement. Yet such a reading is undermined, perhaps even before it can occur, by Adam himself: as readers, we have already experienced Adam making this statement, and reflecting on its multivalence. Throughout the novel, Adam's first-person narration makes the reader privy to the discrepancy between what he says and what he is understood by others as meaning, a gap that is most apparent when he is with Isabel, with whom his 'most intense and ostensibly intimate interactions were the effect of her imbuing my silences, the gaps out of which my Spanish was primarily composed, with tremendous intellectual and aesthetic force' (46). Adam's utterances are shown throughout the novel to be simply prompts for the exercise of meaningmaking on the part of the addressee, but this is unpredictable: Adam at one point expects Isabel to ask that he 'was hers exclusively'; instead, she tells him she already has a boyfriend (93). This uncertainty of meaning is destabilised further by the fact that Adam's silences themselves come to signify; in the context of verbal communication (which necessarily must frame any notion of 
a 'gap' or 'silence') meaning is shown to be predicated on contextual cues, from the 'outside' text.

This uncertainty of effect is further evidence of an irreducible tension between actual and virtual. When discussing the perceived actual - of which the novel's most oft-occurring representation is war - Adam, and those around him, consistently appear to detach themselves to the safety of the virtual, making general pronouncements that have the potential to be made meaningful by the reader or listener. The status of war as 'actual' is therefore made ambiguous; rather than emphasising or decrying the gap that seems to exist between the virtuality of the speech act and the indefatigable reality of war, war is shown instead to be another object that can be discursively repurposed or appropriated. Following Mitchell's statements on the lack of semantic difference between ekphrastic, descriptive and narrative forms of reference, war, or discursive reference to war, is equally flattened to the same dialectical tension between actual and virtual as other objects within the novel. This tension remains open to appropriation by either discourse; 'war' is both cited as actual and treated as virtual throughout the novel, while its signification is similarly dependent on the context of its utterance.

Of course, while in the case of the Franco photograph the caption is a direct quote from Adam's speech, the novel's narrative is in first-person; all of the captions, therefore, are in some sense Adam's words. Indeed, Adam calls attention to the slippage between thought and narration, often beginning extended sections with such statements as: '[t]his is what I felt, if it wasn't what I thought' (64). This further compounds the gap between caption and photograph: that the captions fail to clarify the illustration's meaning is important; equally, the very fact that of their decontextualized recurrence is important in light of the emphasis on context and framing as essential elements of the hermeneutic process. The caption that accompanies the first illustration, the detail from the van der Weyden, is 'I thought of the great artist for a while.' (11). This is a quote from far later in the discourse, when at the end of the novel's third section Adam spends the night at the Ritz with Isabel, before waking to the aftermath of the 2004 Madrid bombings (113). The contexts in which it appears are therefore significantly different. The knowledge of the original context does not negate the quote's ambiguity; who the 'great artist' is remains unclear, though the term also occurs earlier, when Adam speculates about the identity of the man he sees crying in the Prado:

Maybe this man is an artist, I thought; what if he doesn't feel the transports he performs, what if the scenes he produces are intended to force the institution to face its contradiction in the person of these guards. [...] I found myself following 
this man, this great artist, out of the museum and into the preternaturally bright day. (10)

Tracing the caption's provenance in this way does not clarify its meaning; if indeed Adam is, later in the novel, referring back to this scene in the Prado, there is still the central issue of the quote's appearance as a caption far before it occurs as part of a story event. In a novel that otherwise conforms quite strictly to a linear, forward-moving alignment of story and narrative discourse, this discrepancy, and that of the other photograph/caption relationships, stands out. If the caption's purpose is to create a relationship between word and image that signifies, locating part of this joint signifier at a point in the discourse where it is inaccessible to the firsttime reader seems to undermine the relationship itself, or at least force it into one of retrospective enlightenment. This is especially significant in that it highlights the progression of narrative time itself: unlike in a non-fiction book, where such photographs or illustrations, and their captions, have a static meaning independent of the temporal relations within the text, here the entire text is predicated on development - of characters, of ideas, of concepts. Objects within the text are therefore shown to be not just context but time dependent; what is said about an object is not necessarily coherent at all points within the text. Rather than the photograph and caption functioning as a unit, the reference to 'outside' text instead emphasises the process of meaning deferral. The uncertainty surrounding the captions even when placed in the original context mean that even this does not result in a final, non-ambiguous meaning being ascribed to the photograph/caption relation.

The text's embedded images can also be figured in relation to Mitchell's description of the difference between the verbal and visual as one predicated on presence. The art object, when understood as being of the visual, spatial, or plastic kind, is conventionally considered to be essentially present in the world in a way that the verbal can never be. In this sense, physical contact with the art object might therefore prompt the profound experience of art that is unavailable when the art object is apprehended visually. The haptic nature of the art object is emphasised in Leaving the Atocha Station: the motif of a child touching a painting recurs throughout, and Adam himself is drawn to touch a Picasso during his time in Barcelona:

...there were two young kids, six or seven. I didn't see the rest of the family. One walked up quickly to a large canvas and pawed it, clearly on a dare. Both kids ran out of the gallery, presumably back to their parents. There was no guard around. I approached the canvas the child had touched, a miniature precursor of, or study for, Les Demoiselles d'Avignon. I double-checked no one was around and, since the world was ending, touched the painting myself. (158) 
This desire to come into physical contact with the art object is important, as it emphasises the perceived phenomenological difference between encountering an object in the 'virtual' world of the mental, and in the physical, material, and sensual world of the 'actual'. Yet nothing comes from Adam's touching the painting; the art object remains at a distance despite his physical contact with it. The emphasis on the physicality of the art object is further complicated by the inclusion of the photographs: the visual arts' apparently more simple relation to the world - i.e. their being a part of the 'actual' through their spatial presence - is undermined by the fact that these photographs are located within another physical object: the book itself. Further, the photographs exist within the novel as reproductions: they are cropped (often dramatically, as in the case of the Descent detail), printed in grayscale and are, inevitably, of a poor quality. In some cases, this is pronounced: in the photograph of the bombing of Guernica, there are visible horizontal lines across the picture, a trace of the printing process and therefore of reproduction itself (52). Unlike the language of art criticism, which fictional discourse can simulate almost exactly, the photographs in the novel are clearly quite different objects from the originals they reproduce. We might therefore read the images as evincing the loss of aura Benjamin discusses, highlighting the inefficacy of reproductions as substitutes for the 'actual' art object. But this would be a mistake: while the referential distance seems to increase, the manner of the photographs' inclusion within the text makes them physically commensurate with the surrounding discourse: both are printed, and both gesture towards an essentially absent object. As the recurrent reference to touching a painting suggests that there is no essential quality to the physical original, so too do the images evince a flattening of the hierarchy of the visual and textual, with regards to representative distance or mediation. The photographs and their captions therefore cannot be defined within the paradigm of the textual or the visual phenomenological encounter.

The art object's materiality continues to be a concern throughout the novel. In the aftermath of the bombings, Adam visits his friends Arturo and Teresa at their art gallery in Salamanca. The opening planned for that night has been cancelled; instead, at Adam's suggestion, the paintings are to be covered with black cloth as a memorial, 'a visual moment of silence' (121). Yet covering the paintings in this way does not achieve the desired effect; rather than becoming moments of silence, the covered paintings themselves look 'like contemporary art', with their accompanying placards stating names and prices still uncovered (139). As in the case of Adam's own gaps and silences, the covered paintings still signify, but this signification remains open. There is an obvious sense of cynicism here - both Adam and Teresa wonder whether any of the paintings will sell in their covered state - in that the performance of a ritualistic hiding of the art 
object does not nullify, and perhaps even enhances, its status as a commodity (124). Yet the covered paintings also initiate an ontological line of thinking: if both the form and the content of the art object are obscured, the only thing which remains is the work's objecthood itself - its presence in the world. In the case of the covered paintings, the space they occupy becomes the only 'actual' thing about them, yet they are still subject to a dependence on context. As 'objects', they are not somehow detached from signification through their new appearance, but still exist within a nexus of contextual cues for meaning-creation: the placards, importantly, and their location within the gallery environment itself. These elements are important in that they dictate in part any response to the objects as art, but it is equally important to consider how the phenomenological encounter that occurs with such an art object is altered in comparison to their pre-covered, representational state. The emphasised 'objecthood' of the contemporary art work changes the manner in which the spectator interacts with the work; Michael Fried's wellknown theorising on 'literalist' (minimalist) art argues that such works distance the viewer both physically and psychically - due to their 'nonrelational, unitary character', prescribing the relational dynamic as one where the viewer is the subject and the work is the object (Fried 154). Though this subject-object relationship seems typical of all human encounters with the visual or plastic art-object, Fried argues that this relational paradigm is imposed on the viewer in such a way that the encounter becomes one of theatricality, which, he writes, is the 'negation of art' (Fried 153). Theatricality is for Fried to do with an awareness of one's own subject position, and therefore an awareness of perception and mediation itself. Objecthood and theatricality are, for Fried, thoroughly imbricated; the literalist sensibility is one in which the category of objecthood replaces, or at least vacillates between, painting and sculpture, with this material presence becoming the work's only claim to a secure identity. As with his encounter with the van der Weyden, Adam's response to the covered paintings belies an attention to the physicality of the thing itself, rather than any particular formal or representational features. Because the paintings are covered Adam becomes aware of the mediation of the art object - including wondering whether they will sell. Again, then, an emphasis on the object position concomitantly results in its final accessibility being cast into question.

This kind of subject-object relationship is treated with demonstrable ambiguity in the novel. Again, while it is possible to read a relationship of opposition into the categories of 'virtual'/subjective and 'actual'/objective, Adam's own encounters with art objects do not result in the privileging of either one category. This is consistent with other aspects of the novel. One of Adam's key personality traits is that he lies to get attention: most conspicuously, he tells both Isabel and Teresa that his mother is dead, before 'confessing' that she is alive but unwell, living 
with his 'fascist' father: 'As I said this, I thought of my dad patiently trying to get a spider to crawl from the carpet onto a piece of paper so he could escort it safely from house to yard' (86). In addition to this, after an instant message conversation with his friend Cyrus, Adam appropriates the story Cyrus tells him of witnessing a girl drowning in Mexico. A small part of Cyrus's story concerns the aftermath of the drowning:

CYRUS: [...] A couple of people from the restaurant got in a car and went for them. And an old woman, she brought us some limes.

ME: limes?

CYRUS: She brought us two lime wedges and said something about the shock and that we should suck them and we did... (75)

What seems like an insignificant detail - the old woman bringing the limes - is nevertheless repeated in Adam's reproduction of the story to Isabel:

I paused again, lighting a cigarette. Why was my Spanish so halting? "She did not know how to swim. She had bad luck and the current carried her. We followed her. We found the body in the river. I gave her"-here I touched my mouth and then gestured towards Isabel's- "to make her breathe. But it was too late. We took her body to a place with phones. We called the police. An old woman gave us limes."

"Limes," Isabel confirmed.

"She gave us limes for sucking because we suffered shock."

"My God," Isabel said and took my hand. (95-96)

Adam repeats the detail about the limes not because of its significance to the events he describes, though the extra veneer of detail does add a sense of truth-to-life. The limes, as material, sensual objects, anchor his narrative in the physical world. Yet the limes Adam cites are, of course, thoroughly of the virtual; he himself has never experienced them as physical objects. That a physical object could give the weight of the actual to the virtual is undermined: the categories of the virtual and actual are shown to be open to manipulation. Cyrus himself already suspects his girlfriend will repurpose the story herself in her novel. As with the ekphrastic mode earlier in the novel, the repetition of the limes demonstrates how all objects, artworks or otherwise, are essentially irreducible to both verbal representation and to thought.

In a broader sense, then, the art objects described in the text represent a larger reconfiguration of the relation of object and subject as thought through the textual. Artistic configurations are, throughout the novel, referred to in relation to their objecthood and presence in the world, but rather than this physicality confirming the actual/virtual distinction it instead emphasises the irreducibility of the tension between them: objecthood in fact increases the potentiality of the virtual. This extends, or intersects with, the textual: Adam is a poet, and the novel contains two poems purportedly authored by him. The first is embedded in the discourse during Adam's 
appearance at a poetry reading (40). In a similar manner to the relationship between the embedded photographs and their captions, this poem poses a problem because it is made up completely of phrases from the surrounding narrative discourse: 'Under the arc of the cello / I open the Lorca at random', the poem's opening lines, are found earlier in the narrative as Adam describes his poetic process of 'translation':

I opened the Lorca more or less at random [...] I looked up the Spanish word for the English word I wanted to replace, and then replaced that word with an English word that approximated its sound ("Under the arc of the sky" became "Under the arc of the cielo," which became "Under the arc of the cello"). I then braided fragments of the prose I kept in my second notebook with the translations I had thus produced ("Under the arc of the cello / I open the Lorca at random," and so on). (16)

Again, the relationship of the narrative discourse to the art object within it is ambiguous. It would be impossible to locate which came first - the poem or the novel - because of the virtuality - the fictionality - of the whole. The second poem in the text further complicates matters due to its existence in the 'real' world outside the novel: Adam reads the poem in a 'tiny magazine published in New York', a copy of which he had given to Teresa (127). As with the first poem, this work is embedded into the text, and, again, it contains phrases that can be found in the surrounding discourse: the poem's final lines, 'I have never been here. / Understand? / You have never seen me', are found towards the end of the novel, slightly changed: 'I have never been here, I said to myself. You have never seen me' $(128,178)$. The poem's ambiguity is compounded, however, because it exists as an object in the world outside of Leaving the Atocha Station: Lerner published the poem in his collection The Lichtenberg Figures in 2004, the year in which the events of Leaving the Atocha Station take place. While the attribution of the poem's authorship is thus complicated, a more significant effect of this real-world existence is that, like the ekphrastic mode and the presence of the photographs, it forges a connection to the supposed material, non-textual world 'outside' of the novel that is not simply deferral, in the manner of classic poststructuralism. Rather than increasing connection to the actual - seeking the 'real', as James Wood might put it - such devices instead highlight the lack of an actual, accessible object in the world outside the text.

In addition to the two poems 'written' by Adam, Leaving the Atocha Station also contains much consideration of the poem as an abstract thing. Poetry is constantly referred to within the novel as being obsolete - despite Adam's status as poet - due to its inherent virtuality. While at the aforementioned poetry reading, Adam is preceded by a Spanish poet, Tomás, whose work he 
describes as 'an Esperanto of clichés', but which - unexpectedly, to Adam's mind - seems to move the audience:

If people were in fact moved, convincing themselves they discovered whatever they projected into the hackneyed poem, or better yet, if people felt the pressure to perform absorption in the face of what they knew was an embarrassing placeholder for an art no longer practicable for whatever reasons, a dead medium whose former power could be felt only as a loss- these scenarios did for me involve a pathos the actual poems did not, a pathos that in fact increased in proportion to their failure, as the more abysmal the experience of the actual the greater the implied heights of the virtual. (38)

The suggestion here is that the relation between actual and virtual is not so much dialectical as oscillatory - as the actual withdraws, the virtual expands to fill the gap it leaves. Compare, though, Adam's conception of poetry earlier in the novel:

Poetry actively repelled my attention, it was opaque and thingly and refused to absorb me... and yet by refusing to absorb me the poem held out the possibility of a higher form of absorption of which I was unworthy, a profound experience unavailable from within the damaged life, and so the poem became a figure for its outside. (20)

In this sense, the poem as object is both actual - 'thingly' - and virtual. As in the case of the covered paintings, the contextual cues -the fact that the poem is itself an art object - mean that the reader or spectator begins the hermeneutic process with an assumption of referential capacity. This dependence on context, though, means that as the poem becomes increasingly abstract and refuses to easily yield meaning it becomes, to the reader 'opaque' and 'thingly'. In other words, rather than projecting towards the spectator as in Fried's schema of the object, the poem's objecthood causes it to withdraw from the reader, simultaneously becoming increasingly dependent on the ability of the reader to correctly interpret 'outside' texts in order to find meaning while signalling the impossibility of accessing the object itself. The connection between abstraction and 'thingliness' therefore parallels the dialectic of virtual and actual, in that it is in the intersection of the concepts that experience is located. The relationship between subject and object, then, is one of constant projection, regardless of the level of presence the object reveals.

In the above quote, Adam's direct reference to Adorno - the 'damaged life' - is significant, as there are clear parallels between Adorno's concepts and the schema implied in Leaving the Atocha Station. Taken from the subtitle to Minima Moralia, the idea of the 'damaged life' is key to understanding Adorno's criticism as whole. Adorno's concern as a critical theorist is not to provide an account of what the 'good life' would be like, but to examine what the present, 
'damaged life' is like (Jarvis 9). Adorno therefore rejects the idea of a theory that seeks an 'outside' perspective from which to critique. This immanent critique is in contrast to both György Lukács and Benjamin - each of whom are, of course, enormously influential on Adorno's thought - who argue for, respectively, a totalising mode of criticism based on the revolutionary praxis of the proletariat, and a recourse to the 'higher domain' of theology (Jarvis $8-10) .^{7}$ Such a major difference in approach requires some unpacking in order for its significance - and relevance - to be made clear.

Adorno's thought coalesces around the formulation of 'a critical thinking without transcendental method', that is, a philosophical materialism (Jarvis 148). It is this that results in his negative dialectic, and which distinguishes it from the Hegelian dialectic - which, as Adorno conceptualises it, remains within the tradition of German idealism in that it still posits access to an 'absolute truth' (Jarvis 16). The object cannot be translated into thought, thus the negative dialectic 'respects that which is to be thought-the object-even where the object does not heed the rules of thinking' (Adorno Negative 141). Adorno is equally suspicious, though, of any theory that attempts to break with previous modes of thought, as to do so would mean thought would become detached from history, and therefore destined to repeat the dialectic of enlightenment'. The idea of the negative dialectic, then, is not to provide an inversion of a currently 'positive' dialectic, but to demonstrate that truly dialectical thought is already negative in character (Jarvis 168). This 'negativity' is derived from the fact that when seen in opposition to identity thinking - the mode of thought that defines the object by categorisation - the negative dialectic does not attempt a new mode of thought, but instead demonstrates the insufficiency of the present, inescapably identificatory, one. This is what is meant by a reflection on the 'damaged life': according to Adorno, criticism may only discuss the condition of the present - the damaged life - as to do otherwise would be to fall into the mode of contemplative reinforcement of the present (Lukács) or transcendental method (Benjamin).

As a concept, then, the negative dialectic functions non-productively. Rather than assuming the primacy of the subject over the object, Adorno argues that the subject is essentially dependent on the object: the object remains when a subject (human or otherwise) is absent, but the subject position can only ever occur in relation to something external to it (Adorno Negative 141). This leads Adorno to his conception of the identity and non-identity of the object: stated reductively,

\footnotetext{
${ }^{7}$ Relations between Adorno and Lukács and Adorno and Benjamin are too wide-ranging to give an overview of here, and Adorno does refer to both theorists at length in his work. The classic text in which Adorno and Benjamin respond to one another is Aesthetics and Politics; for a brief overview of the relationship between Adorno and Lukács's aesthetic thought, see Timothy Hall's “Adorno's Aesthetic Theory and Lukács's Theory of the Novel" in Adorno and Literature.
} 
an object's 'identity' is what the subject can identify about it - its 'dimensions' and 'blues', for example. Adorno's theory is significant here in connecting such identification with the idea of exchange value, or the formulation of the object's equivalence to other objects. In contrast, the object's 'non-identity' is the ever-present gap in the subject's attempt to identify; it is what causes the object to resist being enmeshed in a network of exchange. This non-identity is not directly accessible to the subject, hence it forms the basis of the negative dialectic: a thinking against thought wherein the subject resists the attempt to identify, and thereby reduce, the object. As Adorno states: 'To proceed dialectically means to think in contradictions, for the sake of the contradiction once experienced in the thing, and against that contradiction' (Adorno Negative 144-145). Adorno does not argue that such a dialectic will finally provide a synthesis, but that it will solely provide an account of the insufficiency of current thought. In the case of Leaving the Atocha Station, then, Adorno's negative dialectic is useful in providing a theoretical basis for the idea of the 'non-identical', inaccessible aspect of the object: the novel is significant in finding this inaccessibility in all objects, whether haptic and material or 'virtual'.

While there is strong evidence for reading such a parallel in the novel, the question remains: why refer at such length to Adorno here? Such theoretical intertextuality is not in itself unique, especially within contemporary literature. Employing the work of a theorist who wrote and thought in a historical moment quite removed from the context of the production of the text at hand runs the risk of removing both theory and novel from history completely. Yet the references to critical theory in Leaving the Atocha Station are not simply evidence of the education of the protagonist, nor do they function solely as interpretive cues. Consider, for instance, Adam's numerous paraphrases of Lukács. During a winter spent mostly in his apartment, Adam wonders:

...if the incommensurability of language and experience was new, if my experience of my experience issued from a damaged life of pornography and privilege, if there were happy ages when the starry sky was the map of all possible paths, or if this division of experience into what could not be named and what could not be lived just was experience, for all people for all time. (65)

This easy reference to major critical theorists is, of course, evidence of Adam's carefully constructed persona of the 'serious' poet, but it would be a mistake to read it as solely that. The adoption of critical discourse is, as in the earlier reflection on the van der Weyden, unattributed. Adam is quoting, here, but there is no indication of this within the discourse itself: neither Lukács nor Adorno are mentioned by name at any point in the novel. This is important: Adam's 'voice', such as it is, incorporates such discourse fluently; it would be easy to assume that these 
are his words, and to some extent the lack of direct citation means that they are his words. Of course, it would therefore be possible to parse the passage as further evincing Adam's disconnect from the 'real' world and subsequent flight into the abstraction of theory, but as consideration of the other objects in the novel has shown, this distinction does not always hold. The reference to Lukács is important here because of its subject matter: Lukács's 'happy ages' of the epic refers to a speculative time in which language and the world were commensurate, during which, significantly, there would be no need for philosophical or theoretical contemplation (Lukács Novel 29). Adam follows Lukács in ascribing to his present moment the impossibility of its representation - whether that be textual, visual, or critical - framing this impossibility not simply as one of language, but of the relationship between subject and world. Critical theory therefore becomes not a flight from the world, but an essential part of the experience of it, when the world is understood as being essentially inaccessible. Theory, like the photographs or the poems, is part of an attempt at communion with the materiality of the present, a materiality whose primary characteristic is its non-identicality, its refusal to be directly identified or experienced by the subject.

Thus far, I have been using the terms 'thing' and 'object' interchangeably in reference to the art objects present - or present to some (virtual) degree - in the novel. This lack of distinction, however, is perhaps misleading. 'Object' as a term implies a specificity which 'thing' does not; further, while philosophy is accustomed to understanding the 'object' as signifying, this is not the case for the 'thing'. Bill Brown's introduction to 'Thing Theory' is useful here:

As they circulate through our lives, we look through objects (to see what they disclose about history, society, nature, or culture-above all, what they disclose about $u s$ ), but we only catch a glimpse of things. We look through objects because there are codes by which our interpretive attention makes them meaningful, because there is a discourse of objectivity that allows us to use them as facts. A thing in contrast, can hardly function as a window. (Brown 4)

Materialism, in the case of the object, refers to an essentially semiotic process; the object is used as a site for hermeneutics. In contrast, the 'thingness' of an object - what Fried might call its objecthood - only becomes subject to attention when it stops functioning as we have come to expect - 'when the drill breaks, when the car stalls, when the windows get filthy', or, perhaps, when the painting is covered (Brown 4). Yet as Brown continues, 'thing' also denotes a kind of amorphousness; it is 'concrete yet ambiguous', functioning 'to overcome the loss of other words or as a place holder for some future specifying operation' (Brown 4-5). Here, then, the connection to Adam's categories of virtual and actual becomes more apparent: if the thingness 
of an object is part of both its objecthood and its virtuality, so too is the virtual a category of both potentiality and materialism.

Despite the embedded photographs and poems, then, there is no recourse to a final materiality within Leaving the Atocha Station. The photographs are reminders of the thingness of the art object, but the ambiguous nature of their relationship to the surrounding text makes it impossible to consider them as wholly of the material world. This liminality is gestured towards throughout the novel. During the aforementioned winter, Adam is keenly aware of how the uneventful forward motion of his lived experience would be impossible to translate into narrative:

These periods of rain or periods between rains in which I was smoking and reading Tolstoy would be, I knew impossible to narrate, and that impossibility entered the experience: the particular texture of my loneliness derived in part from my sense that I could only share it, could only describe it, as pure transition [...] But this account ascribed the period a sense of directionality, however slight or slow, made it a vector between events, when in fact the period was dilated, detached, strangely self-sufficient, but that's not really right. (63-64)

What enters Adam's thinking here is the concept of duration: of how time affects and effects things in the world. Adam continues: '[d]uring this period all like periods of my life were called forth to form a continuum, or at least a constellation', the latter term important for its provenance in critical theory (64). Conceived by Benjamin, the 'constellation' as later borrowed by Adorno represents 'a juxtaposed rather than integrated cluster of changing elements that resist reduction to a common denominator, essential core, or generative first principle' (Jay 1415). The use of 'constellation' here again emphasises the inaccessibility of the non-identical; in connecting the idea of time to the idea of the constellation, the implication is that it is not just the materiality of the object, but its presence in both space and time, which accounts for the complexity of the phenomenological encounter the spectator has with it. Constellations, as employed by Adorno, are 'nothing in themselves' but relations 'between (necessarily timebound) particulars' which might allow a glimpse of the non-identical, an illumination of the specificity of the individual thing (Jarvis 176-177). Adam's account of his life's duration demonstrates an understanding of what he identifies as the 'constellation' as itself being life, with events themselves, 'sharply localized occurrences in time', being 'mere ligaments' (64). These events, he continues, cannot be represented accurately because of their conventionality they are, in his words, 'ready-made literature' - and yet the constellation itself is not representable because it is nothing in itself. Following Adorno, then, it becomes possible to understand these 'events' as 'time-bound' concepts, while duration itself becomes the 
constellation. Representing the concept in itself (i.e. the non-identical) is always impossible because of the inherent inescapability of identity-thinking; as Adam says, such concepts as the 'kiss' or 'concussion' cannot be understood in themselves as they are always already thought through conceptuality. Yet the negative dialectic is not able to offer any way out of this representational inadequacy: it can only demonstrate the insufficiency of one mode of thought, can only reflect on the 'damaged life' as it presently exists.

These 'time-bound particulars' - the concepts whose relations form the constellation itself - are important, in that the entire schema must be understood as being in motion; Adorno does not think that concepts can remain fixed unless they are empty. If the concepts are not fixed, however, the problem in understanding the constellation comes in accounting for how such a schema can be cognized as differing from the transcendental schema Adorno rejects. There is much to be said on Adorno's interlocution of the transcendental schema in Kant; in essence, however, Adorno rejects Kant's appeal to the transcendental because he believes that to admit a philosophy which does not allow the subject to have any knowledge of the object, except for what appears to the subjective consciousness, is essentially a kind of scepticism. In other words, Kant argues that we can only know objects phenomenally, though we can think of a thing 'considered as it is itself (Jarvis 182). Adorno argues that this schema is unintelligible, as for the subject to think of the thing 'in itself' it must have knowledge of such an essence existing 'beyond appearances', yet this very knowledge of the essence would surely imply that it had in fact appeared to the subject (Jarvis 182). Adorno argues instead for a 'priority of the object'; that is, the object as independent of the subject and its conceptuality, though he maintains that immediate access to the object, outside of conceptuality, would not be possible, as this would always be mediated by the subject's consciousness. Yet while such a priority seemingly implies a recourse to materialism, Adorno again rejects this, claiming that such a schema implies that the object itself is an 'invariant ground' rather than something mutable and in flux.

To clarify the nature of a subject-object relation predicated on movement, it is worth returning to Lukács. As discussed, his Theory of the Novel centres on the notion of immanence, of a commensurability of subject and object. In contrast to the epic's 'happy ages' of subject-object coevality, the novel is the form of 'absolute sinfulness': a categorisation (inherited from Fichte) that does not necessarily imply a moral judgement but instead signifies a kind of relational dynamic, or 'perspective', between subject and world (Lukács Novel 152). As described by Timothy Bewes: 
The novel is the form of 'absolute sinfulness' not because of any moral or historical decline, but simply because of this principle of interiority, the principle that creates and maintains the 'chasm' between self and world, condemning the novel to abstraction, reflexivity, pontification, irony or utopianism. (Bewes Escape 40)

This subjective perspective, predicated on interiority, is therefore implicit in the novel; it is also what makes the form so problematic for Lukács. Towards the end of the Theory of the Novel, this inherent division between subject and world is contrasted with the suggestion of a 'new world' where such perspectival relationships cease to exist. Here Lukács parallels Adorno’s conception of the 'damaged life' in arguing that the 'new world' cannot be represented as this would itself involve a perspectival configuration of subject to world. There thus seems to be a kind of vanishing point or aporia for critical inquiry at this point. As Bewes points out, however, the very suggestion of a 'new world' apart from such perspectival relationships in The Theory of the Novel is preceded by the description of the cinematic medium in the early essay "Thoughts Toward an Aesthetic of the Cinema" (Bewes Escape 42). The essay is explicitly concerned with the relationship between the cinematic image and its represented object(s); importantly, however, Lukács is not concerned with the representational distance between cinematic image and object, but with the fact that cinema seems to offer an escape from such questions altogether (Bewes Escape 41).

One of the key elements of Lukács's cinema essay is his description of the 'essence' of cinema: this, he states, is 'movement itself, an eternal variability, the never-resting change of things' (Lukács Cinema 15). This sense of movement and change is predicated on the 'unlimited possibility' cinema offers; rather than the sequence of shots being bound by causality, shots are connected only in that 'they follow one another, immediately and without transition' (Lukács Cinema 15). It is in this condition of possibility that cinema differs most concretely from the novel; as Lukács figures, in cinema, 'everything is true and real, is equally true and equally real' (Lukács Cinema 15). Whether cinema was or is finally able to offer such a condition is of little relevance here; what is important, however, is the utopian potential Lukács identifies in the medium, a potential that is wholly predicated on its treatment of time. It might seem, of course, that Lukács's account of cinema is paradoxical: if the 'new world' cannot be depicted or else become enmeshed in the network of representational exchange it is supposed to overcome, how is cinema able to offer such a utopian vision in the present moment of its existence? The key here is that cinema, for Lukács, does not attempt to represent life at all; as he argues, the cinematic image means, 'only movements and actions of people - but no people' (Lukács Cinema 14). Rather than being an alternative to present life, Lukács figures cinema as an 'aspect' of the same life, 
...a life without the present, a life without fate, without reasons, without motives, a life without measure or order, without essence or value, a life without soul, of pure surface, a life with which the innermost of our soul does not want to coincide; nor can it [...] The world of the "cinema" is thus a world without background or perspective, without any difference in weight or quality, as only the present gives things fate and weight, light and lightness (Lukács Cinema 14)

Interiority - subjectivity - is what produces a perspectival relationship; rather than a 'new world', then, it is perhaps more accurate to characterise Lukács's vision as a revolutionary transformation of the subject position itself. The gesture towards a world in which the subject is coeval with the object equals a situation in which, '[m]an has lost his soul; in return, however, he gains his body' (Lukács Cinema 16). This latter emphasis on the body thus suggests a subjectworld relation in which the interiority of the subject is sacrificed for the 'sensory immediacy' of the cinematic image, or as Lukács later figures it, the epic (Bewes Escape 46). Subject-object relations in Lukács are therefore based in sensual experience rather than representation.

Lukács's work on cinema is finally useful, then, in expanding the definition of what the world of the 'epic' might actually feel like. More than just a utopian vision of a world in which 'the fire that burns in the soul is of the same essential nature as the stars', the world of the epic - which I have here, following Bewes, conflated with the cinematic medium - is one in which form is interlocuted according to its sensual qualities (Lukács Novel 29). The immanent properties of the novel as a formal and technical category - rather than the perspectival relationship it has to the world it represents - must be commensurate with the sensory experience of the world; it is not that representational distance must be reduced to the point of indistinguishability, but that the question of representation itself must be replaced by a formal coevality between the novel and the 'outside' world. Cinema, then, is useful in offering a glimpse of how this mode might be figured, but in Lukács's later work, what becomes clear is the extent to which such a transformation must be predicated on, to use Bewes's words, 'the insight that language, too, is a 'mechanical' apparatus, as 'seared' by reality as the photographic image' (Bewes Escape 47).

If we understand Lukács's essay on cinema as adumbrating a formal mode or category whose defining character is its condition of possibility, it becomes clear that the temporal (or durational) logic of the cinematic image is immensely useful when brought into dialogue with narratological analysis of the novel itself. As previously stated, the art objects in Lerner's novel serve in part to disrupt and draw attention to the duration of narrative time: photographs are captioned with quotes from as yet unread parts of the discourse, and duration itself is discussed through reference to the textual or cinematic media through which it might be reconstructed. Lukács's conception of cinema is of particular interest because it is predicated on an 
understanding of time that differs from the conventional understanding of story progression; its 'unlimited possibility' is due to the ability of each individual shot to exist independently. Yet this conception of cinema seems somewhat lacking. If cinema is at least in part a narrative medium - a contention which, to my mind, does not seem subject to debate - then this is surely predicated on exactly the kind of connection between images - the 'temporal sequence' - that Lukács identifies as defining the novel mode itself. There seems to be no essential difference between the nature of cinematic time as conceived in Lukács and the nature of novelistic time as evinced by Lerner; both media seem capable of producing narratives that are made coherent only through the necessarily singular temporal direction of their experience. In light of the novel's disruption of medium specificity, it makes more sense to understand the cinematic/novelistic time distinction as based not on medium but on a way of perceiving and understanding time. This argument does not negate the above discussion of what Lukács conceived in the cinematic medium, but it does bring into question what the essential ontological difference between cinematic and novelistic time might be, a question that is important to consider in light of Leaving the Atocha Station's concern with duration itself.

Perhaps, then, it will prove useful to compare Lukács's largely ignored essay on cinema with Gilles Deleuze's enormously influential Cinema books. Rather than critiquing one theorist through the lens of the other, a more useful paradigm for engagement is to bring both into a dialogue while remaining conscious of the extremity of difference existing between the historical moments of their writing. Deleuze's comprehension of cinema as a medium is influenced by the huge amount of cinematic texts available to him; Lukács, in contrast, was writing much earlier and thus his essay makes some arguments that seem untenable today:

The "cinema" presents mere action but no motive or meaning. [...] It is for this reason - and only apparently due to the present day imperfections of technique that the scenes of the cinema are silent. The spoken word, the sounding concept, are vehicles of fate, only in them and through them arises the binding continuity in the psyche of the dramatic character. (Lukács Cinema 15)

Language is here identified as the element which enforces linear temporality - that is, conventional, novelistic forward movement. Again we see in Lukács a separation of cinematic and novelistic narration; it is helpful, then, to refer to Deleuze for an alternative way to conceptualise this difference. Deleuze's most pressing distinction is not between cinema and novel or silence and speech; his Cinema books are predicated on a divide he calls the 'sensorimotor break', which marks a division between the classical cinema of the 'movementimage' and the 'time-image' of the modern. While the nature of this break is never wholly 
clarified, the distinction Deleuze draws here is important in that it is not solely theoretical, but can be found in aesthetic praxis. Rather than conceiving of cinema as a whole, the 'sensorimotor break' allows the problem outlined with Lukács's argument above to perhaps be overcome, or at least avoided, by Deleuze. Unlike Lukács (and Adorno), Deleuze does not offer a totalising theory of immanence without representation, but identifies a particular kind of aesthetic configuration - the cinema of the time-image - that itself gestures towards a nonperspectival relationship between actual and virtual.

Deleuze defines two categories of cinema: the movement-image and the time-image. The difference between these images lies in the different ways they apprehend the actual and virtual. The time-image culminates in the crystal-image - a shot that occupies a unique place in space and time through its virtuality: the virtual, for Deleuze, refers to the interpenetration of past and future through the present. The crystal-image is necessarily complex; essentially, it emphasises the indivisible unity, or what D.N. Rodowick describes as the 'indiscernibility', of the virtual and actual image (Rodowick 92). It is a portrait of duration in the sense that Bergson, from whom Deleuze draws his theory of time, defines it: 'Pure duration is the form taken by the succession of our inner states of consciousness when our self lets itself live, when it abstains from establishing a separation between the present state and anterior states' (Bergson 100). In this context, the distinction between actual and virtual is based on description, as Rodowick continues, 'the actual refers to the states of things - the physical and the real - as described in space through perception. The virtual is subjective, that is, mental and imaginary, sought out in time through memory' (Rodowick 92). Deleuze again inherits much here from Bergson, whose own argument centres around the notion that there is no difference between interior and exterior, subject and object - that both are simply 'systems of images', interacting with each other in a 'perceptual and/or epistemological event' (Rodowick 30). Though the BergsonDeleuze encounter is not predicated on a subject without interiority, as in Lukács, the subject position outlined is one in which the virtual is formally congruent with the 'actual': both are systems of images that can interact with one another in an 'event'. It is important to note, however, that the crystal-image description can rarely be applied to an entire film; for Deleuze, while many films contain the crystal-image or variations of it, this usually applies only to a single shot. The crystal-image as a category therefore remains somewhat speculative, despite its basis in aesthetic praxis.

The crystal-image is therefore of essential importance in understanding how Deleuze might be meaningfully discussed in relation to Lukács's configuration. If the subject-world (and text- 
world) relation must be one of formal and technical congruence, the time-image seems to be the only realised aesthetic category in either theorist's work in which such a relation might be achieved without a concomitant descent into referential paradox (as discussed by Adorno and Lukács on separate occasions). In order to understand how Deleuze's direct image of time might prove productive in discussion with Leaving the Atocha Station, it is first necessary to consider what, according to Deleuze, precedes it: the movement-image or the 'organic regime' (Deleuze 126). The movement-image consists of action and reaction in a spatial rather than a temporal sense. The key difference is therefore between each image's relation to, or understanding of, the object it represents:

A description which assumes the independence of its object will be called 'organic'. It is not a matter of knowing if the object is really independent, it is not a matter of knowing if these are exteriors or scenery. What counts is that, whether they are scenery or exteriors, the setting described is presented as independent of the description which the camera gives of it, and stand for a supposedly pre-existing reality. In contrast, what we will call a crystalline description stands for its object, replaces it, both creates and erases it - as Robbe-Grillet puts it - and constantly gives way to other descriptions which contradict, displace, or modify the preceding ones. It is now the description itself which constitutes the sole decomposed and multiplied object. (Deleuze 126)

While this concern with representation might seem in contrast to Lukács, the very usefulness of Deleuze lies in the predication of the sensorimotor break on a difference not just of representational distance or adequacy, but in the mode or type of image-world relation. What Deleuze identifies in the movement-image is its conventional relation to the world, and to time. Taken as an ontological category rather than a cinematic technique, the movement-image assumes a prior objective world that can be represented - to whatever degree of accuracy - in art or discourse. Such a category, when applied to narrative, means understanding the story and narrative discourse distinction as functioning in a single direction; story need not precede narrative, but can be extracted from narrative and pieced together by the reader or viewer to form a coherent whole. The movement-image might therefore be equated with a classical understanding of the novel form: time can only be registered through the sequential (forward) movement of events - 'event' here meaning an action, rather than the Bergsonian concept defined above. In contrast, the time-image is a condition of constant production: neither story nor discourse can be understood as prior, but are instead indiscernible and constantly developing.

Towards the end of Leaving the Atocha Station, Adam visits Barcelona with Teresa. At one point, they discuss Antonioni's film The Passenger - Teresa draws a comparison between Adam and 
herself and the characters of Jack Nicholson and Maria Schneider. Teresa describes the film's iconic final shot to Adam - who has not seen the film, but pretends he has - before going on to talk more about films, seemingly without Adam's involvement:

...Teresa talked about films, almost none of which I knew; maybe because we'd seen Orpheus, a movie about fluid boundaries, earlier that day, or because we were suddenly and impulsively arrived in a new city, or maybe because the bar was like a cave, I projected images to accompany her speech. Teresa appeared in those images, entered the films she was describing, and soon the films collapsed into one film, and it was her life I was imagining. She didn't so much recount plots as shots and sequences as though they were plots. I pictured her at various ages and at the center of each scene, as if she had organized it around herself, and this struck me as a higher form of biography than the mere detailing of events. (153)

This 'higher form of biography' is one in which the formal features of the medium are commensurate with the represented object; the technical categories of 'shots and sequences' replace the conventional narrative mode of the representation of a series of events. It is significant, in a novel so concerned with the 'damaged life', and the impossibility of representing the 'new world', that what occurs here seems to be a very specific description of an aesthetic category that is coeval with its object. Of course, this form exists only within Adam's imagination; the form of the novel dictates that such a mode might be thought or glimpsed, but never wholly realised.

In Leaving the Atocha Station, the limits of the novel mode mean that the kind of 'new world' thought by Lukács, or the Deleuzian crystal-image can only be gestured towards. The novel's final lines come while Adam is at the launch of a chapbook of his poetry:

Arturo appeared at the podium and began to speak. Night-blooming flowers refused to open near the stadium lights. Freedom was on the march. Aircraft noise was having strange effects on finches. Some species synchronized their flashes, sometimes across thousands of insects, exacerbating contradictions. Why was I born between mirrors?

Teresa would read the originals and I would read the translations and the translations would become the originals as we read. Then I planned to live forever in a skylit room surrounded by my friends. (181)

In the final paragraph Adam again imagines an interpenetration and indiscernibility of past and present, actual and virtual. The idealism - even utopianism - in the final sentence is obvious. In the preceding sentences the insistence on dialectical configurations is also clear: the synchronicity that serves to exacerbate 'contradictions'; the 'born between mirrors' line (itself a repetition: the line is from Lorca, and first appears in the original Spanish two pages earlier); 
and, of course, the imagined simultaneity of original and translation. ${ }^{8}$ Yet these concepts, in remaining both dialectical and idealist, can finally only act as a suggestion of something of which the novel form is itself incapable. If Deleuze's movement-image can be thought of as congruent with the depiction of time in the novel, the time- and crystal-images must therefore be thought of as an alternative category of text-world relation that, despite the specificity implied by its description in the Cinema books, remains impossible to realise in full. While modern cinema might offer glimpses of the direct image of time, Deleuze argues that very few films extend this beyond the individual shot or sequence. As in the other configurations of subject-world relation discussed - Adorno's negative dialectics and constellations; Lukács's categories of the 'epic' and 'new world' - the situation of the text in its own historical moment means that all such imagining remains just that. Through continually positing a dialectical relation between text and object, subject and world, 'actual' and 'virtual', Leaving the Atocha Station finally suggests an overcoming of considerations of representation and perspective. Yet this gesture does not make the novel idealist or utopian in character. While the continued gesturing towards a configuration that is unachievable within the context of the textual medium must necessarily be understood as idealist, such gestures also demonstrate the recognition of the limitations of the novel form itself. As the constellation might offer glimpses of the nonidentical, rather than attempting to perform within the novel the ideal subject-world relation Leaving the Atocha Station makes reference to its absence through both content, and, perhaps more significantly, through form.

\footnotetext{
8 To Lorca, compare Rodowick on the crystalline-image: 'Like an image produced in a mirror, it always has two poles: actual and virtual' (Rodowick 92).
} 


\section{The Sensuous Presence of the Thing: Infinite Jest}

If Leaving the Atocha Station can be broadly construed as a novel of determinate negation, in which the embedded art objects and ekphrases consistently gesture towards the impossibility of accessing the object completely, I want here to outline a schema in which the opposite is the case. This chapter is concerned with how the representation of art objects in a literary text might serve to undermine, rather than reinforce, aspects of the novel's form and content. David Foster Wallace's Infinite Jest, while being superficially very different from Lerner's novel - it is approximately six times longer, with a non-linear, third-person narrative focalised through a number of different characters - provides a productive contrast. Despite their myriad stylistic differences, in both novels the embedded art object can be placed under greater heuristic scrutiny than if it were simply providing a veneer of detail, or evincing a particular kind of metafictional recursion. The embedded art objects of both novels have in common a relation to the surrounding text that reveals how the novel as a whole is conceived as relating to the world. Yet, as I will argue, despite their shared investment in the art object, Wallace's novel does differ from Lerner's in deeply significant ways. These differences are apparent not just on the level of form or content, but in the aesthetic assumptions on which each novel is predicated. The representation of art objects therefore provides a productive spectrum through which to focus on and analyse subject-object relations on an internal level, and to investigate whether these relations are consistent with the novel as an art object itself.

A key point of difference between the ekphrastic mode in Leaving the Atocha Station and Infinite Jest is in the relative fictionality of its objects. Lerner's novel describes artworks of various media - painting, photography, film - including those which exist outside the novel and those that are purely fictional (as well as complicating the provenance of others, such as Adam's poetry). The novel also includes visual art objects - reproductions of photographs and film stills - alongside the more conventional ekphrastic passages. In contrast, in Infinite Jest the art 
objects described are almost exclusively fictional. ${ }^{9}$ This places a particular pressure on the question of aesthetics as the text itself becomes the only point of access for the reader. In this sense, the art objects of Infinite Jest - despite initially seeming less complex than those described in Leaving the Atocha Station - pose a challenge to critical analysis of the novel: it is important here to remain focused on how the art objects are figured through ekphrasis, rather than only speculating as to what they might look like outside of the novel. In what follows, then, I want to outline how Infinite Jest's concern with the art object reveals that the novel's position on the relation between subject and object is itself contradictory. Through returning to the critical apparatus already developed - particularly the work of Adorno and Deleuze the aesthetic and metaphysical assumptions on which Infinite Jest is based can be extrapolated and analysed in relation to the text of the novel itself.

In Infinite Jest, the clearest examples of ekphrasis are filmic. If the term ekphrasis refers to the verbal representation of the visual, the textual representation of cinema can thus be described as ekphrastic because - like the more traditional painting, sculpture, or objet d'art - cinema is non-textual. Perhaps more so than with other media, however, the representation of cinema seems to be inescapably subject to Mitchell's 'ekphrastic indifference', that is, 'the commonsense perception that ekphrasis is impossible' (Mitchell 151) While Leaving the Atocha Station can approximate the paintings it describes through photographic reproduction (though the efficacy and effect of such reproduction is limited), the descriptions of, and the cropped still from, Antonioni's The Passenger only reproduce one aspect or moment of the film. In this sense, cinema is a peculiar object for ekphrasis in that the subject's phenomenal relation to a cinematic object is always inherently and obviously mutable; cinema is not just a visual but an explicitly time-based art, and thus unlike the perception of stasis that comes with painting or sculpture, it is an object based not just on existence in space but in time. On the level of form, however, the relation between the cinematic object and its textual representation becomes more complicated, in that both media share a temporal direction: just as a film can be described as a number of shots in time, so a novel consists of words on a page which are read from beginning to end. Both media have an external chronology - the time it takes to watch a film, or read a book, and an internal chronology - the sequential forward movement of events in the narrative. The relationship between cinema and the novel is further complicated by each art object's mode of representing this second chronology: if we follow Deleuze, the classical

\footnotetext{
9 The most prominent exception to this comes in the recurrent references made to Gianlorenzo Bernini's statue The Ecstasy of St Theresa, an art object which has great significance in the novel, and which is returned to later in this chapter.
} 
cinema of the movement-image should be quite easily approximated by the novel's inherent teleology; it is more difficult to imagine how the time- and crystal-images might find their textual equivalent. In analysing the fictional cinematic objects embedded in Infinite Jest, in particular how such objects relate to the surrounding discourse, we can therefore gain an insight into how the novel figures duration itself.

The most useful point of departure for analysing the novel's ekphrastic objects comes in the fictional oeuvre of J.O. Incandenza, experimental filmmaker and father to Orin, Mario, and Hal Incandenza. References to Incandenza's work are scattered throughout Infinite Jest, most notably in sections focalised through Hal and Joelle van Dyne - ex-girlfriend of Orin and actor in Incandenza's films - and in the 'filmography' found in one of the novel's many endnotes. Unlike Leaving the Atocha Station, all art objects within Infinite Jest are figured textually; their 'mediation' is therefore more explicit, although as I hope to have shown, the idea that the visual is somehow representationally superior to the textual when dealing with embedded art objects is not sustainable. This is not to say, however, that the manner in which Incandenza's films are rendered is of no consequence; quite the opposite. The wholly textual nature of the embedded art objects in Infinite Jest makes their fictionality more pronounced while also allowing them to blend seamlessly with the surrounding text. The way in which Incandenza's films are figured therefore provides the most compelling evidence of the aesthetic sensibility that runs through the novel.

In addition to biographical details, J.O. Incandenza is introduced as a filmmaker early in the novel. As with the majority of Infinite Jest, the section is narrated in third-person, the films described as

...'après-garde' experimental- and conceptual-film work too far either ahead of or behind its time, possibly, to be much appreciated at the time of his death in the Year of the Trial-Size Dove Bar - although a lot of it (the experimental- and conceptual-film work) was admittedly just plain pretentious and unengaging and bad (Wallace Jest 64)

At the end of this quote is an endnote: the aforementioned 'filmography', an eight-page list of Incandenza's films. Each entry gives the name, date, 'major players', storage medium's 'gauge or gauges', and distribution medium, among other details (986). The filmography therefore operates semi-ekphrastically, describing an essentially absent art object in detail. In doing so, it draws attention to the inadequacy of textual representation of the cinematic: reading the entire filmography brings the reader no closer to the phenomenal experience of viewing the work. 
Mitchell's category of 'ekphrastic indifference' seems to hold true here, at least according to the novel's internal logic.

The idea that textual representation is insufficient in describing its object is further exacerbated by the filmography's parody of academic discourse. Fictional academic articles are cited throughout the filmography, following academic convention exactly though often including playful or parodic titles, for example:

Romney and Sperber, 'Has James O. Incandenza Ever Even Once Produced One Genuinely Original or Unappropriated or Nonderivative Thing?' Post-Millennium Film Cartridge Journal nos. 7-9 (Fall/Winter, Y.P.W.), pp. 4-26 (990)

Parodying academia in this way reiterates a disconnection between what is spoken or written about art objects and the experience of the art objects themselves. Despite the length and exhaustive detail of the endnote, little can be understood about what Incandenza's aesthetic and filmic choices might actually look like. Further, the tone of ironic detachment prevalent throughout points fun at the enterprise of film theory in general, suggesting an inevitable, insurmountable gulf between literary and cinematic texts. While the 'filmography' as a mode is defined by its objectivity - it should act simply as a catalogue or record - the filmography in Infinite Jest is not solely taxonomic. The attention to creating a surface of academic convention and bibliographic detail means that the filmography has a somewhat paradoxical function, parodying academic discourse while performing its minutiae exactly. While the reader is never asked to believe that the filmography corresponds to any non-fictional art object, when individual films are described using what amount to simple value judgements - language that would of course be out of place in a 'real' filmography - such pronouncements have an implicit sense of validity, even if this validity only holds true in the fictional world. In addition, the use of rhetorical devices to argue a certain point about Incandenza's work - the parody of academic vernacular in the latter quote, and in the former a predicate of value judgement arrived at in a sentence that begins without bias - establish a further level of distance between reader and film than what might occur through conventional or traditional ekphrasis. The text's mediatory function is made obvious through the use of parody and irony as rhetorical devices, but in highlighting this mediation the novel suggests its inverse: that there is some final, authentic experience of the art object, but that such an experience cannot be rendered through text.

While the filmography provides an overview of Incandenza's work, Infinite Jest also includes sections in which characters' own relations to the films are described. As the star of a number 
of Incandenza's late films, Joelle van Dyne might be expected to provide a less complex example of how cinematic objects are figured in the novel. Joelle's background and continued interest in 'Film \& Film-Cartridge Theory' mean that within the novel she is something of an expert; her responses and judgements are therefore imbued with a sense of authority, and lack the obvious alienating effect of the filmography's academese. Under her stage name, 'Madame Psychosis', Joelle hosts the radio show 'Sixty Minutes More or Less', which consists of monologues described as 'both free-associative and intricately structured', with the 'one even remotely consistent theme' of film (185). One of the film movements Joelle is said to be exceptionally knowledgeable about is 'anticonfluential cinema', which, as detailed in an endnote, is

An après-garde digital movement, a.k.a. 'Digital Parallelism' and 'Cinema of Chaotic Stasis,' characterized by a stubborn and possibly intentionally irritating refusal of different narrative lines to merge into any kind of meaningful confluence, the school derived somewhat from both the narrative bradykineticism of Antonioni and the disassociative formalism of Stan Brakhage and Hollis Frampton, comprising periods in the careers of the late Beth B., the Snow brothers, Vigdis Simpson, and the late J.O. Incandenza (middle period). (996)

Like many of the works and movements with which Incandenza is associated, 'anticonfluential' cinema is treated by both the characters and narrator(s) with a kind of ironic disdain: while never overtly mocked, the theory is aligned with the same tediously academic, non-communicative aesthetic category gestured towards in the filmography. That this lack of narrative convergence is 'intentionally irritating' is an opinion echoed in Joelle's own thoughts - again narrated in third-person - on Incandenza's filmmaking. In an extended analysis late in the novel, Joelle describes Incandenza's cinematic work as

More like the work of a brilliant optician and technician who was an amateur at any kind of real communication...no narrative movement toward a real story; no emotional movement toward an audience...like a very smart person conversing with himself $(740)$

Here, narrative progression is conflated with an emotional connection with the viewer. As in the endnote quoted above, aesthetic categories (the lack of narrative 'confluence', 'formalism', etc.) become signifiers of value or lack thereof.

The fictionality of the 'anticonfluential' means that - along with all Incandenza's cinematic work - the only access point the reader has is the text itself. It is impossible to separate the art object from how it is figured in the text because there exists no art object outside the text; thus, any method of critique that attempts to analyse such concepts or objects will be 
necessarily speculative. In examining the evidence provided to support the claim that Incandenza's films are 'unengaging and bad', however, we can infer a clear system for the assignation of aesthetic value that also has implications for the ontological schema of the novel. The film "The Joke" is particularly useful in this regard, in that it is the most extreme representation of the problem Joelle finds in Incandenza's work. Its entry in the filmography reads:

The Joke. B.S. Latrodectus Mactans Productions. Audience as reflexive cast; 35 mm. x 2 cameras; variable length; black and white; silent. Parody of Hollis Frampton's 'audience-specific events,' two Ikegami EC-35 video cameras in theater record the 'film' 's audience and project the resultant raster onto screen the theater audience watching itself watch itself get the obvious 'joke' and become increasingly self-conscious and uncomfortable and hostile supposedly comprises the film's involuted 'antinarrative' flow. Incandenza's first truly controversial project, Film \& Kartridge Kultcher's Sperber credited it with 'unwittingly sounding the death-knell of post-poststructural film in terms of sheer annoyance.' NONRECORDED MAGNETIC VIDEO SCREENABLE IN THEATER VENUE ONLY, NOW UNRELEASED. (988-989)

The film's conceptual and self-referential nature is alienating, but more than that the film forces its audience into an uncertain phenomenological position of vacillation between subject and object. In this sense, reading "The Joke" in relation to Fried's dictum on 'literalist' art is useful. As summarised by Robert Jackson, 'literalism' means that there is a specific onus on the spectator to 'complete' the artwork, whereas the modernist artwork is autonomous: 'already complete, unified' and 'beheld as such' (Jackson 143). “The Joke” is described as further negating the object's possible autonomy; not only does the spectator need to be present in order for a 'complete' artwork to exist, there literally is no artwork outside of the spectator. If Fried's 'theatricality' results from the subject's self-awareness as subject, in "The Joke" this is compounded by further effacement of the object until the 'artwork', such as it is, would consist only of the technical apparatus bringing it into being (the camera, projector, and screen) and the frame of context provided by the location of experience (the cinema or art gallery in which the film is projected, and more specifically, the space between projector and screen). The spectator's position is therefore revealed to be essentially performative, but while "The Joke" suggests that such a response to the art object might not be restricted to this particular work - that is, the spectator is always in some way responding to contextual cues in order to perform an appropriate response to an object as 'art' - because there exists no object at all, in the filmography such context-dependence and performativity is dismissed as 'sheer annoyance'. In this way, "The Joke” parallels ekphrasis because no object actually exists - only fiction - and therefore only the response to, and description of it exists. While "The Joke" is 
something of an exception in its extremity, it highlights how the novel's aesthetic sensibility might be usefully aligned with Fried's theorising of autonomous art, and is thus at odds with the novel's own apparently non-autonomous form. The configuration - and manipulation - of subject-object relations is of central importance in understanding how Incandenza's work is figured in the novel, and perhaps more importantly, why it is figured as 'pretentious and unengaging'.

Through the access points available, it is clear that the novel's fictional films represent a particular aesthetic. This aesthetic, predicated on a disruption of the spectator's perspective of the art object, is throughout the novel described in negative terms. Major characters - Joelle included - do not ascribe value to the majority of Incandenza's oeuvre, while the various parodies of academia and film scholarship serve both to discredit Incandenza as a filmmaker, and to make ridiculous the entire enterprise of (film) theory in general. If ekphrastic hope is, as Mitchell describes it, an attempt to overcome the medium specificity of the literary and the visual arts, in Infinite Jest this is instead highlighted by the fractured accounts given of Incandenza's work. The novel's cinematic objects thus remain subject to Mitchell's ekphrastic indifference, despite their fictionality.

While the examples used here are necessarily limited, the idea that Infinite Jest to some degree endorses medium specificity is one echoed in recent Wallace scholarship. In his essay "Representing Entertainment(s) in Infinite Jest', Philip Sayers analyses the ekphrastic passages that describe Mario's own films, arguing that through highlighting the different temporalities of the discourse and the film - due to various digressions the former progresses more slowly than the latter - the novel also highlights the different possibilities of each medium (Sayers 356). Sayers concludes that the novel's final position with regard to medium specificity is ambivalent; Infinite Jest, he claims, is irreducibly hybrid in form and is thus a 'powerful call for balance' between 'high and low culture, and reading and spectating' (Sayers 361). While Sayers's conclusion is logical, he fails to acknowledge the effect of ekphrasis outside of questioning the representational adequacy of different media. This leads to the central problem with his conclusion: to suggest that Infinite Jest might be read as demonstrating such a 'balance' between high and low culture is to pay attention only to the text's surface - its easy reference to pop culture, both real and imagined - while ignoring the central role occupied by the question of aesthetic value. The content and rhetoric of those ekphrases concerned with Incandenza's films suggest a schema in which the inability for the reader to access them is derived from the inability of Incandenza to produce sufficiently involving art objects, rather 
than the impossibility of accessing any object completely. Thus, the central problem with the accounts given of Incandenza's work in Infinite Jest is that the twin assumptions of medium specificity and aesthetic autonomy through which it is critiqued are themselves neither acknowledged nor interlocuted. What is essentially an ontological problem is confused with a question of value.

So far, I have discussed how the novel describes Incandenza's work in general, and in the specific case of "The Joke". Conspicuous in its absence has been the most important art object described by the novel: "Infinite Jest" itself. ${ }^{10}$ Unlike the other films in the novel, the nature of "Infinite Jest" means that no character is sufficiently able to describe or represent the work after viewing it. The film thus inhabits a peculiar position - while it is commonplace for ekphrasis to describe fictional art objects, the purpose of such description is in part to convey to the reader what an aesthetic object is like, an enterprise made possible due to the object's presence in the fictional world. "Infinite Jest" is an unusual object for the ekphrastic mode because both the reader and the characters in the novel can only speculate as to what it might be like. Further, in an interview with Helen Steeply of O.N.A.N.'s 'Unspecified Services' Joelle points to the possibility that within the storyworld of the novel, "Infinite Jest" might not exist at all: ${ }^{11}$

I don't know that he ever even got a finished Master. That's your story. There wasn't anything unendurable or enslaving in either of my scenes. Nothing like these actual-perfection rumors. These are academic rumors. He talked about making something quote too perfect. But as a joke. (940)

Joelle's account is useful in giving an account of "Infinite Jest" that both negates and confirms various aspects of the film previously established by the discourse, primarily through the exchanges between Steeply and Marathe. In this sense, the art object is again gestured towards but not accessed through text, but contra Lerner, this sense of contextual meaning creation does not enter the experience itself. As with "The Joke", the question of whether any aesthetic object even exists is raised; in contrast to the earlier film, however, this uncertainty extends not just to the object's fictional subjects, but to the reader of the text. While "The Joke" is described as controversial and audience-hostile due to its non-autonomous nature, "Infinite Jest" instead emphasises the non-autonomous nature of the novel's form. The reader uses the various contextual cues the novel provides to imagine an embedded art object where none

${ }^{10}$ Following established convention, in this thesis the novel's name is italicised while the fictional film is in double quotation marks.

11 O.N.A.N. - the organisation of American nations - is the name given to the former United States and parts of Mexico and Canada in the novel; 'Unspecified Services' is the equivalent of the C.I.A.. 
exists, a process consistent with all ekphrases but highlighted here by the characters' own inability to access the work.

The gestures towards "Infinite Jest" are also important in understanding the novel's implicit aesthetic schema. While Joelle suggests that the 'too-perfect' concept is likely false, her description of the lenses used in the creation of the film suggests that it is the film's formal features - its technical and optical qualities - that are behind its powerful effects:

I don't think there's much doubt the lens was supposed to reproduce an infantile vision field. That's what you could feel was driving the scene. My face wasn't important. You never got the sense it was meant to be captured realistically by the lens. (940)

Steeply, much earlier in the novel, describes the efforts of the O.N.A.N. scientists to understand the film, telling Marathe:

Tom Flatto's personal theory is the appeal's got something to do with density. The visual compulsion. Theory's that with a really sophisticated piece of holography you'd get the neural density of an actual stage play without losing the selective realism of the viewer-screen. That the density plus the realism might be too much to take. Dick Desai in Data Production wants to go in with ALGOL and see if there are Fourier Equations in the root code's ALGOL, which would signify hologrammatical activity going on. (490-491)

Joelle and Steeply's accounts differ, in that while Joelle suggests that "Infinite Jest" is (at least partly) shot in order to replicate an 'infantile vision field', Steeply and the O.N.A.N. scientists believe that it is its 'neural density' that is most affecting. ${ }^{12}$ The reference to holography in the latter theory is important; an oblique reference to holography previously occurs (in the discourse; the section itself is the last chronological story event) when Hal states that he, 'believe[s] Dennis Gabor may very well have been the Antichrist' - Gabor, a physicist, is best known for inventing holography (12). The indicators that "Infinite Jest" might be holographic in form are difficult to understand: the nature of holographic projection is quite different from standard film or photographic projection, and no indication is given in the novel that the InterLace Entertainment cartridges are capable of recording holographic material. However, these oblique references to holography remain productive points of analysis in Infinite Jest as in addition to emphasising the importance of its formal features, thinking through "Infinite Jest" in relation to holography allows a return to the categories of virtual and actual previously discussed. The image projected from a holograph is called a 'virtual' image; the nature of the image is thus fundamentally different to the regular photographic image. Steeply describes a

\footnotetext{
12 See also pp. 490, 993 for references to the possible holographic properties of "Infinite Jest".
} 
theory wherein the 'neural density' plus 'selective realism' might be 'too much' for the viewer to take. Both descriptions suggest particular kinds of subject-object relations; what Steeply appears to claim is that through a particular kind of technique, "Infinite Jest" offers both a suggestion of density or depth - consistent with the idea of holography - situated within the frame of the screen. This would therefore create an image or series of images that had the illusion of real depth and existence in space while remaining paradoxically small and screenbased. The power of "Infinite Jest" to incapacitate, then, would derive from the spectator's perception of a disjunction between the virtual image and the actual moment of the film's viewing; Hal identifies Gabor as the 'Antichrist' because he created a technology that prompts the feeling of reality while it remains a simulation. Again, then, it is clear that the novel is based upon a schema in which actual and virtual remain separate and distinct, wherein the virtual is always the lesser of the two categories.

The value schema implied by "Infinite Jest" is complicated, however, because as an art object it is itself virtual: it is imagined, fictional, gestured towards only in text. Yet through the suggestion of optical and holographic effects, "Infinite Jest" is figured textually as a virtual art object that seems to exceed the boundaries of the virtual: its formal perfection is achieved through the simulation of reality. Deleuze's account of the actual and virtual is again of use here. To reiterate the overview from the previous chapter: the 'sensory-motor break' refers to the move from the movement-image to the time-image; it therefore also refers to a movement from the image of the actual to the image of the virtual. The actual, as the present moment of the 'real', corresponds to lived experience: when we are considering action we exist in the category of the actual. Deleuze derives his conception of time from Bergson; the 'time' referred to in the Cinema books is not spatialised clock time, but duration. In this context, the actual can be understood as the present moment (in a spatial sense), but the term also indicates a particular relation to the lived world of reality, i.e. the experience of reality in the present. In contrast, the virtual signifies those categories - such as memory or fantasy - that can be 'imaged' in the present moment. To clarify this point, Deleuze posits two axes, again inherited from Bergson: the horizontal axis of duration, wherein the future moves into the past through the present, increasing our stores of memories; and the vertical axis, expansion upon which entails movement away from the present moment into the virtual, primarily through memory and dream (Rodowick 10). While Deleuze's conception of this schema is perhaps not as clear-cut as this overview suggests, for the purposes of this chapter a basic understanding of these axes is sufficient. 
"Infinite Jest" is described as drawing the viewer away from the present moment and thereby immobilising them; the viewer becomes static and catatonic due to being stuck on the vertical axis. In this sense, the viewer's engagement with the film is harmful because through stimulating only the virtual, no actual action occurs - hence the exaggerated result of catatonia and stasis. The nature of the film as described in the text further suggests it represents the virtual in both form and content. The holographic and optical properties cause the viewer to perceive a simulated depth of field - a 'neural density' - that does not actually exist, while the content of the film - as far as Joelle's account is accurate - replicates the perspective of an infant. Memory - recognition and recollection - are categories of the virtual; the employment of an infantile perspective therefore correlates to an expansion upon the vertical axis of the virtual. What is perhaps most interesting about drawing a connection between "Infinite Jest", Infinite Jest, and Deleuze's actual/virtual distinction is the extent to which the productive possibilities of the virtual are never suggested; unlike Leaving the Atocha Station, the categories of actual and virtual in Infinite Jest remain imbricated in a value schema that seems to extend beyond the terms of the novel. There is no question that, as readers, we are to conclude that "Infinite Jest" and its results are harmful; within the fictional world of the novel, this is a coherent coalescence of aesthetic and metaphysical concepts. Yet as with the other aspects of Incandenza's filmmaking, though the nature of the embedded art object means that accounts of it are inescapably mediated, the fact that this mediation in language - especially when it takes the form of the ekphrastic mode - is inherently virtual and produces virtual, fictional art objects is never reflected upon. In other words, unlike Deleuze, and to an extent Lerner, the characters (and narrators) in Infinite Jest are consistent with one another in their aesthetic tastes to the extent that aesthetic and metaphysical categories such as those of 'actual' and 'virtual' become part of the novel's generalised value schema. According to this schema, the 'virtual' is wholly negative, with expansion upon the vertical axis representing a solipsistic retreat into the self and subsequent immobility and stasis. This is in direct contrast to Deleuze, for whom the virtual is a category of production, of possibility and of the potential for difference. If the actual corresponds to the present moment of action, it also corresponds to the necessity of the present moment and the moments that follow, and can thus be broadly construed as teleological in the same way as the novel. Deleuze's account of the virtual, however, describes a condition in which the movements into the past and future away from the certainty of the actual, lived moment result in a moment-to-moment freedom and the possibility of difference. The virtuality of "Infinite Jest" - its mutability and productive potential - is therefore 
circumscribed by both the novel's form and its underlying assumption about the nature of subject-object relations.

The filmic ekphrases in Infinite Jest therefore imply a particular aesthetic value schema and its contingent subject-object dynamic. That the virtual is suppressed and dismissed in the novel is significant because it demonstrates how the relation between duration and the art object is conceptualised in the novel. As described by Rodowick, Deleuze's direct image of time replaces the 'deterministic universe' with a 'probabilistic' one (Rodowick 15). In other words, as opposed to the teleological temporal progression found in the classical indirect image of time (and the conventional novel), through the direct image of time the condition of productive possibility is accessed. What makes this difference productive for the present discussion is that Deleuze defines the movement- and time-images aesthetically - that is, through form. A key way in which the time-image departs formally from its classical precursor is in the kind of cut used: the 'rational' cut of classical cinema determines 'commensurable relations between series of images' - therefore giving an indirect image of time - contra the 'irrational' cut, wherein the cut itself becomes important due to its non-relation to the images surrounding it: 'Instead of one image after the other, there is one image plus another, and each shot is deframed in relation to the framing of the following shot' (Deleuze 213-214). ${ }^{13}$ The sensory-motor break is therefore aesthetic, but for Deleuze such an aesthetic shift implies a larger shift in the perceptual relationship between 'man and the world' (Deleuze 173). To return to the categories of actual and virtual, the ekphrastic objects of Infinite Jest inhabit a liminal space: they are wholly virtual, yet within the novel their value is assessed according to a schema in which the virtual is not just inferior to the actual, but non-existent. The novel therefore operates paradoxically: by suggesting that virtuality means an object does not exist, it undermines those points at which the actual - as understood by the novel - is gestured towards. If the virtual has no meaningful relation to the actual, the novel itself is made redundant and superfluous despite its conceptualisation of an accessible actual.

In light of this schema's priority of the actual, it is significant that the only non-fictional art object represented in the novel is a statue: by definition it is haptic and immobile. While the descriptions of The Ecstasy of St Theresa are no more of the actual than those that refer to Incandenza's films, the recurrent - albeit brief - references to the statue suggest that within the novel it is understood to prompt a different kind of experience from Incandenza's

\footnotetext{
${ }^{13}$ An example of the use of the irrational cut given by Deleuze is Bresson, whom both J.O. Incandenza and Joelle admire to various degrees. Bresson is one of the filmmakers Joelle, as Madame Psychosis, is said to refer to 'sometimes' on her radio show (185). Late in the novel, in a Hal-narrated section, we are told in passing, 'Like the Parisian-French Bresson he so admired [J.O.] had no interest in suckering the audience with illusory realism' (944).
} 
'pretentious' and 'unengaging' films. Just before Joelle attempts suicide, she thinks of the statue: 'the saint recumbent, half-supine, her flowing stone robe lifted by the angel in whose other hand a bare arrow is raised for that best descent ... the angel's expression not charity but the perfect vice of barb-headed love' (235). Here, the statue's perceived stasis provides Joelle with a singular point of ecstasy, but she is only imagining the statue and the actual encounter it might provide. In Deleuzian terms, Joelle is therefore moving along the vertical axis - because she can only imagine the statue her experience is figured as an escape from the actual world. The statue itself remains a fixed point. The very idea of escape or transcendence through accessing such a 'real' object is evidence of an ontological hierarchy that is incoherent when situated within the fictional world of the novel; that The Ecstasy of St Theresa is the model for such an object is important due to its inherent properties: its stasis suggests the atemporal, ahistorical way in which the novel understands object relations.

The concept of stasis in Infinite Jest has been subject to some critical attention. Jeffrey Karnicky argues that it is itself productive, in a reading that employs Deleuze and Guattari's $A$ Thousand Plateaus for support. Karnicky takes the recurrent moments of what he calls 'asignifying stasis' throughout the novel as being points of catalyst and transformation, because 'stasis points are points of subjectification that are not reducible to a root or unifiable to a world picture' (Karnicky 121). Rather than an illusion of stasis being taken as evincing an autonomous and immobile actual object, Karnicky argues that the various points of stasis act as catalysts for action - that is, the subject experiences stasis as part of the actual, action-oriented world. Following the reading of Deleuze I have presented her, however, such stasis would surely be impossible because the 'actual' is constantly in flux and is defined by its basis in action. That my own argument is so different to Karnicky's, despite our shared use of Deleuze's theory, is perhaps evidence of the changing nature of the latter's ideas. Yet, to my mind, Karnicky's argument is flawed not because his reading of Deleuze is wrong, but because he reads Infinite Jest as being itself rhizomatic, as formally corresponding with the 'flat multiplicities' of $A$ Thousand Plateaus. This represents a radical underreading of the novel; as I hope to have demonstrated thus far, to suggest that Infinite Jest articulates an ontological or aesthetic flatness ignores that its central organising principles are hierarchical.

The hierarchy implied by Infinite Jest's references to The Ecstasy of St Theresa is also evident in the novel's narrative structure. Far from being rhizomatic in nature, the form of Infinite Jest continues to suggest a schema based on clear distinctions between the actual and virtual. Infinite Jest's narrative is non-linear: it begins with the final story events of its chronology. This 
is, of course, a common structural device, though the sheer length of Infinite Jest exacerbates any difficulty the reader might have in reconstructing the story. It is this last point that is important here: despite its appearance of formal ingenuity, Infinite Jest still relies on the existence of an underlying teleology for coherence: unlike Incandenza's 'anticonfluential' cinema, the fractured nature of the narrative discourse is supposed to be reconstructed. The non-linear narrative is a kind of game for the reader, or, in Wallace's words, a necessary piece of work that must be undertaken in order to receive the gratifying result of narrative coherence: ${ }^{14}$

It's supposed to be uneasy. For instance, using a lot of flash-cuts between scenes so that some of the narrative arrangement has got to be done by the reader, or interrupting flow with digressions and interpolations that the reader has to do with work of connecting to each other and to the narrative ... if it works right, the reader has to fight through the mediated voice presenting the material to you. (McCaffery 137)

While later in the quoted interview Wallace emphasises the importance of drawing attention to this mediation, the form of Infinite Jest itself is still predicated on the idea that 'the material' is somehow distinguishable from its form. In this sense, the novel mirrors the movementimage's assumption of the relation between subject and world; that is, it assumes the independence of its object, and, crucially, also assumes that this independence remains regardless of the presence of the camera (or, in this case, regardless of the narrative discourse). Wallace's use of 'through' here is also important, in that it suggests a singular direction: the reader's movement is predetermined. The reader's intellectual 'work' is therefore in service of accessing the 'actual' - the 'material'. Again, the implication is that the novel's relationship to the world is fixed, that it simply acts as a bridge between the static categories of the subjective and objective. That the 'material' and its mediation - or the story and the narrative discourse, in this case - could be separated is a premise regarded with some suspicion within narrative theory: in her essay "Narrative Versions, Narrative Theories" Barbara Herrnstein Smith argues that such a dualistic model of narrative discourse evinces a 'naïve Platonism', and is 'not only empirically questionable and logically frail but also methodologically distracting' (Smith 213, 231). There is therefore a parallel to be drawn between the unsustainability of the story/narrative discourse distinction and the construal of the categories of actual and virtual as separate and unrelated, even when the very form in which they are found would seem to negate such clear-cut categorisation.

\footnotetext{
14 Though this work can be outsourced: see, for example, Stephen Burn's David Foster Wallace's Infinite Jest: A Reader's Guide, which includes a fully reconstructed chronology of the novel's events.
} 
A further key figure in understanding the schema upon which Infinite Jest is predicated is Mario, the middle Incandenza brother. ${ }^{15}$ While Joelle's character development suggests movement towards redemption - or at least away from addiction - Mario remains static. ${ }^{16} \mathrm{He}$ is perhaps the least critical or reflexive character in the novel, and is described as intellectually

...slow, Hal's brother is, technically, Stanford-Binet-wise, slow, the Brandeis C.D.C. found - but not, verifiably not, retarded or cognitively damaged or bradyphrenic, more like refracted, almost, ever so slightly epistemically bent, a pole poked into mental water and just a little off and just taking a little bit longer, in the manner of all refracted things. (314)

Despite - or more accurately, because of - this, Mario is central to the novel's aesthetic and metaphysical schema. Because Wallace associates intellectualism with the virtual and therefore with disengagement and solipsism, Mario represents a kind of ideal subject, but the fact that it is his disability which results in this subject position makes him a strange kind of martyr figure. As 'the least cynical person in the history of Enfield MA', he is firmly on the side of those values the novel espouses as 'good': sincerity, authenticity, lack of irony (184). Significantly, Mario also both believes in God and has his own semi-Christ-like status within the novel, his birth being referred to as, ' $[$ t]he first birth of the Incandenzas' second son' (40-41; 312). Despite his physical deformity, Mario is unashamed and demonstrates no self-pity, placing him in direct contrast with Joelle. ${ }^{17}$ Just as Joelle's purported expertise colours her ekphrastic passages with authority, Mario's lack of cynicism and faith suggest sincerity, authenticity, and a lack of his father's pretension. Mario's ekphrastic passages are therefore informed by the reader's understanding of his role within the novel.

Like his father, Mario is a filmmaker; the two are described as having been 'inseparable' before Incandenza's death (314). While Mario's own cinematic output forms a key element of his characterisation, and is the object of an extended ekphrastic passage in the novel, it is not in the description of film but radio that Mario's role in the novel's aesthetic schema is made clear. ${ }^{18}$ Mario is an avid listener to Joelle's film-centric show 'Sixty Minutes More or Less'; in the narrative present, Mario hears a recording of an episode coming from Ennet House, where Joelle herself is (unbeknownst to Mario) currently a resident. Hearing the show

\footnotetext{
15 Or possibly half-brother. Hints that Charles Tavis, Mario's maternal uncle (though possibly not through blood -Tavis possibly being Avril Incandenza's stepbrother [81; 901]), might in fact be his biological father, abound. See Infinite Jest 312; 314; 316; 451; 901; 1044, note 244).

16 See 590 .

17 Joelle's (possible) deformity causes her to cover her face at all times with a veil, as she is a member of the Union of the Hideously and Improbably Deformed (U.H.I.D.). Mario is approached by a 'veiled legate' from the U.H.I.D. but is asked to leave by his younger brother: 'it was Hal, even as Mario laughed and half-bowed, it was Hal, brandishing his Dunlop stick, who told the guy to go peddle his linen someplace else.' (317)

${ }^{18}$ For a useful description of what is going on in the aforementioned ekphrastic passages surrounding Mario's untitled film (a remake of his father's "The ONANtiad”, with puppets), see Sayers $355 \mathrm{ff}$.
} 
prompts a passage - still in third-person - that is both ekphrastic (i.e. it describes Mario's response to the art object in the narrative present) and describes Mario's historical relationship to the $\operatorname{work}(\mathrm{s})$ :

Mario'd fallen in love with the first Madame Psychosis programs because he felt like he was listening to someone sad read out loud from yellow letters she'd taken out of a shoebox on a rainy P.M., stuff about heartbreak and people you loved dying and U.S. woe, stuff that was real. It is increasingly hard to find valid art that is about stuff that is real in this way. (592)

It is important to note here that Mario's interest in Joelle's work is not in itself problematic. What does constitute a problem for any critical study of the text is that this interest - this value judgement - is contextually-determined by the surrounding text to function as a signifier of aesthetic value in general. Unlike the filmography, the voice used to describe Mario's appreciation of 'Sixty Minutes More or Less' is indistinguishable from the third-person narrator that makes similar proclamations throughout the text. What occurs here, then, is the combination of the ekphrastic mode with the gnomic present: the nature of ekphrasis as a gesture towards an inaccessible object is undermined in order to affix a statement of static, ahistorical truth. If ekphrasis is a mode for describing the subject's experience of the object, the above passage uses this relation to suggest that Mario has full access to the (art) object; through listening to Joelle's show, he accesses a 'real' that is, throughout the novel, determined as the real.

For similar reasons to his appreciation of Joelle's radio show, Mario is a fan of Ennet House itself: the two times he's been invited inside he's felt that 'it's very real' (591). Ennet House's residents are recovering addicts, including - after her attempted overdose - Joelle, and Don Gately, a member of staff to whom Joelle becomes close. Gately is, along with Hal, one of the strongest contenders for the title of protagonist in the novel; unlike Hal, however, he has reached the nadir of his addiction - as is recounted in the novel's final section - and is now on the way to recovery. The key element in this recovery - and, it is implied, in the recovery of all addicts - is his acceptance of the principles of Alcoholics Anonymous (AA). These principles are again demonstrative of how the relation between text and world is construed in the novel. In essence, AA involves accession to a system or schema that is irrational; as one character states, AA 'defie[s] sense...you just [have] to accept it on faith' (533). At the heart of the AA project, then, is a kind of meta-aim: one cannot complete the twelve-step program without first believing that the twelve-step program will work. This involves the same suspension of critical or analytical thought as prioritising the actual over the virtual. The logic of AA also 
requires that one focus entirely on the present moment, in order to overcome the pain inherent in duration, as recalled by Gately:

Feeling the edge of every second that went by. Taking it a second at a time. Drawing the time in around him real tight. Withdrawing. Any one second: he remembered: the thought of feeling like he'd be feeling this second for 60 more of these seconds - he couldn't deal. He could not fucking deal. He had to build a wall around each second just to take it. The whole first two weeks of it are telescoped in his memory down into like one second - less: the space between two heartbeats. A breath and a second, the pause and gather between each cramp. An endless Now stretching its gull-wings out on either side of his heartbeat. And he'd never before or since felt so excruciatingly alive. Living in the Present between pulses. (859-860)

The idea of 'Living in the Present' is one of many platitudes through which the AA program functions; it also corresponds almost exactly to the action-oriented Deleuzian definition of the actual. The cliché nature of such phrases is highlighted throughout the novel; Geoffrey Day, Ennet House resident and former academic who 'came in saying on his Intake he also manned the helm of a Scholarly Quarterly', is one of multiple characters who criticise AA for this very reason (272). On the AA concept of asking for gratitude, Day states:

...I cultivate gratitude. That's part of the system of clichés I'm here to live by. An attitude of gratitude. A grateful drunk will never drink. I know the actual cliché is "A grateful heart will never drink," but since organs can't possibly be said to imbibe and I'm still afflicted with just enough self-will to decline to live by utter non sequiturs, as opposed to just good old clichés, I'm taking the liberty of light amendment...Albeit grateful amendment, of course. (271)

Day's voice here is inflected with irony: he treats the clichés and platitudes of AA with the same ironic detachment criticised elsewhere in the novel, particularly by and through Mario. Thus, while Day believes himself to be of superior intellect to those around him, in the novel he is the manifestation of the kind of turgid academese parodied in the filmography. ${ }^{19}$ This disparity is further highlighted through Gately's own thoughts on Day:

If Day ever gets lucky and breaks down, finally, and comes to the front office at night to scream that he can't take it anymore and clutch at Gately's pantcuff and blubber and beg for help at any cost, Gately'll get to tell Day the thing is that the clichéd directives are a lot more deep and hard to actually do. To try and live by instead of just say. [...] He tries to feel like Day is teaching him patience and tolerance. It takes great patience and tolerance not to want to punt the soft little guy into the Comm. Ave. ravine and open up his bunk to somebody that desperately wants it, the Gift. Except who is Gately to think he can know who wants it and who doesn't, deep down. (273)

\footnotetext{
19 An article of Day's on the history of the A.F.R. is plagiarised by E.T.A. student Jim Struck; Day's prose is described as resembling somebody 'flecking your forehead with spittle as he ranted grandiosely' (1056).
} 
Again, the emphasis is on action over the perceived flight into the virtual. Gately's self-doubt and mindfulness are in direct contrast to Day's know-it-all attitude. What is of particular interest here however is the way in which the novel combines the idea of a central truth or accessible actual with an aesthetic banality. It is directly because of their lack of traditional formal aesthetic value that the clichés of AA are understood in the novel as being truthful, as being part of the 'stuff that is real'.

In addition to the distinction between actual and virtual, Infinite Jest therefore places in conflict the aesthetic and the anti-aesthetic. Such a conflict is not original to the novel; it is a central concern of critical theory throughout the twentieth century, particularly prominent in Benjamin and Adorno. It is worth, here, returning to their shared - and debated - aesthetic and metaphysical theories in order to expand the arguments I initiated earlier in this chapter. If Infinite Jest is - as I suggest - concerned with outlining a particular aesthetic schema based on a particular kind of subject-object relation, then such a gesture itself evinces the very kind of 'outside' perspective that Adorno so forcefully argues against. Both the aesthetic endorsed, and the fact of this endorsement, are therefore essential parts of the novel's relationship with the reader and with the world. To employ theorists of an aesthetic tradition that existed long before Wallace was writing might appear to fall victim to the kind of historical reasoning that suggests the novel mode can be considered outside of its specific context. Yet the question here is not simply whether Wallace does or does not conform to a historically distant principle. Infinite Jest is a novel that engages explicitly with aesthetic subject-object relations. If Leaving the Atocha Station inhabits a critical or theoretical position inherited from Adorno's negative dialectics, it is also formally consistent with this position; that is, theory and form are congruent throughout. I want to suggest here that Infinite Jest, on the other hand, despite its oft-lauded length, breadth, and depth, is built upon an inconsistent ontology, which the novel's form serves to both highlight and refract.

In engaging the conceptual apparatus of critical theory to interlocute Infinite Jest, perhaps the most useful term from which to depart is that of aura. In Adorno - and again, he is responding to Benjamin - we find the defence of an auratic art wherein the establishing principle is that of distance; that is, aura, as Adorno understands the term, is itself defined by a sense of compounded distance, of the loss or impossibility of aura itself. Adorno and Benjamin are often viewed in opposition when it comes to this idea: Adorno is the elitist, committed to an auratic modernism; Benjamin, on the other hand, is engaged with the reality 
of technical reproducibility and its implications. ${ }^{20}$ Each side argues that theirs enables critical perspective and sociopolitcal praxis to emerge. Yet such descriptions ignore the important shared concerns of both thinkers, as Robert Kaufman writes,

...one may ratify or contest either side's vision of how art best instantiates social labour; yet precisely this labour is crucial to both sides in the controversy. Why? Because not just in Adorno, but at memorable moments in Benjamin as well, aura's trace-presence, its charged distance, its luminous and disturbing conjugations of otherness, had once registered - amongst other things - the potentials of a collective subject's labour power and agencies. (Kaufman 123)

For both Adorno and Benjamin, then, aura and critical agency are imbricated due to the potential inherent in the idea of auratic distance and the intellectual labour required for its apprehension. Kaufman's argument is thus important: not only does it bring further complexity to the Adorno-Benjamin dialogue, it allows a critical apparatus to be developed from Adorno's aesthetic theory that allows for further access and understanding of the idea of thinking against thought through the negative dialectic. The term aura as it is used by Benjamin and his interlocutors is contentious precisely because it is not always consistent; as Miriam Hansen states in "Benjamin's Aura", its meaning and usefulness are dependent upon the particular constellation in which it is deployed. In using the concept of aura in relation to Infinite Jest, then, I want to both acknowledge its historical vicissitude while concomitantly relying on its later adoption by Adorno as an aesthetic category as a way to stabilise, and therefore maximise the heuristic function of, the term for this particular project.

Hansen traces Benjamin's use of the term through materials that precede the famous artwork essay. Aura is found to be a far less delimited concept than much scholarship on Benjamin presumes; as Hansen describes, aura is defined by

...elements of disjunctive temporality-its sudden and fleeting disruption of linear time, its uncanny linkage of past and future-and the concomitant dislocation of the subject are articulated through, rather than in mere opposition to, the technological media. (Hansen 347)

Hansen posits that the artwork essay is thus restrictive in its definition of aura: through connecting it to 'traditional' artworks, Benjamin makes aura pertain to 'the special status of the art object', as opposed to his earlier theorisation that aura is found in all things (Hansen 351). This, according to Hansen, is what Adorno extrapolates into an objective aesthetic category as the 'semblance of autonomy in the work' (Hansen 351). However, while Adorno's use of the

\footnotetext{
${ }^{20}$ For a brief but useful overview of Adorno and Benjamin's conflicting ideas on this subject, see Simon Jarvis, Adorno: $A$ Critical Introduction (1998), pp. 77-80.
} 
term is focused on the artwork, it is also an essential element of his wider metaphysical theory. In this sense, what appears to be a failure on Adorno's part to properly construe the complexity of Benjamin's original concept can actually be understood as consistent with the former's own approach to subject-object relations. In other words, while Hansen is correct that Adorno's concept of aura is centred on the artwork, this does not negate the term's usefulness in relation to his formulation of a larger metaphysical schema.

This connection is clarified through an understanding of the categories of 'aesthetic' and 'antiaesthetic' as used by Adorno. The use of only these terms is perhaps incorrect: the AdornoBenjamin debate has, according to Kaufman, been misconstrued by critics who do not take into account the further difference between the terms 'aesthetic' and 'aestheticization' (Kaufman 124). This latter distinction is of great importance, both to achieving a full understanding of Adorno's aesthetics, and in any attempt - such as this thesis - to relate such ideas to aesthetic objects themselves. As Kaufman explains, Adorno's well-known contempt for certain currents in twentieth-century art is due to their 'anti-aesthetic' sensibility (Kaufman 123). For Adorno, because of the distinction between aesthetic and aestheticist, such an antiaesthetic position 'one-sidedly indict[s] or eschew[s] auratic aesthetic autonomy' and therefore contributes 'to the destruction of genuinely critical response' (Kaufman 124).

As in Kaufman, the lyric mode is central to aura in Hansen's genealogy of the term; it is in the lyric that Benjamin identifies the distancing effect of aura on the subject. According to this account, aura is thus aligned with the kind of art that Fried argues for in "Art and Objecthood". The distance that constitutes the auratic quality of art 'cannot be produced at will; it appears to the subject, not for it' (Hansen 352). However, that auratic art should be conflated with autonomous art is problematic, as the latter term veers dangerously close to making categorical assumptions about what counts as an aesthetic object and what does not, and thus opposes the idea of the art object's contextual dependence. There is a need, here, in light of Hansen's comments about aura, to move away from the term as an essentialising and prescriptive one. To reiterate my earlier point about Hansen's reading, the term remains useful if we assume that it is, firstly, applicable to thinking the otherness of all objects, and secondly (and perhaps more importantly), that auratic art for Adorno is based on the fundamental loss or impossibility of experiencing aura directly; that is, the term is coherent only when acknowledged negatively. Negative aura therefore makes sense when understood as the acknowledgement of the impossibility of an autonomous auratic object - or, at least, in the possibility for the subject to ever experience it as such. 
For Adorno, implicit in the pursuit of the aesthetic is therefore an acknowledgement of its impossibility. In contrast to the anti-aesthetic, a dedication to the aesthetic "paradoxically winds up being anti-aestheticist' (Kaufman 124). Kaufman clarifies Adorno's argument:

Adorno contends that the aesthetic allows for the experimental development of a protocritical consciousness whose aesthetic play or felt spontaneity mimes social labour insofar as artistic making and aesthetic experience tend processively to discover aspects of the social that have been obscured by status quo conceptualizations of the latter; aestheticization, meanwhile, is for Adorno the proper name of an unreflective acquiescence to reification. (Kaufman 124)

Adorno's argument is immensely relevant here: that 'aestheticization' - the anti-aesthetic evinces an unreflective attitude towards the world is an argument supported by the reading of Infinite Jest I have presented here. Adorno's argument shares the logic of those aspects of his thought discussed in the previous chapter. A key point at which Adorno disagrees with Lukács is in the former's insistence on the impossibility of elevating practice over theory; as Jarvis explains, for Adorno any attempt to do so - i.e. to break from negation - results in contemplative reinforcement of the present social and structural reality (Jarvis 188). Though it might seem contradictory for Adorno to then claim that aesthetically committed practice can result in critical agency, his schema is not unintelligible because his aesthetic theory is grounded in the belief that auratic art is already defined by aesthetic distance. Because the antiaesthetic sensibility intentionally abandons aura completely, it fails to even negatively acknowledge what Kaufman describes as the 'crucial modern phenomenon of aura's loss (or at least its apparent loss)' (Kaufman 124). While the pursuit of an auratic art can potentially result in aestheticization and affirmation of the present, it also has the ability to, through its implicit distance, provide a condition of possibility wherein critical agency might occur. In other words, while Adorno recognises the failings of some auratic art, he maintains that the particular kind of aura he theorises is of essential importance in that it allows the subject momentary access to the other, to 'look beyond the walls of the prison' of subjectivity (Adorno Aesthetic 347). ${ }^{21}$

While Adorno's distinction between the aesthetic and the aestheticist is therefore useful, it seems as though we again arrive at a contradiction: if Adorno's metaphysics is grounded on a non-essentialist, non-transcendental philosophy, surely such a 'look beyond' to the other is impossible. Indeed, as Jarvis states, Adorno argues that we could never 'have access to some

\footnotetext{
${ }^{21}$ Kaufman emphasises the distinction between Adorno's 'via negativa' aura and the term as used by 'official culture' to 're-enchant and reconcile a world still scored by profound exploitation and stark inequality' (Kaufman 264 , note 4).
} 
kind of immediate objectivity wholly free of subjective mediation. Any such promise would be delusive because 'cognitive 'access' to immediacy is already a mediation of it' (Jarvis 183). How, then, can this be figured as anything but such a transcendental perspective, predicated on an encounter with an aesthetic object as invariant ground? To answer this question, it is perhaps useful to return to the idea of the constellation previously discussed. If Adorno's looking beyond subjectivity is compared with constellatory form's gesture towards the nonidentical, it becomes clear that a more accurate translation of Adorno's original German here is 'glimpse': subjective cognition is inescapable, but to think otherness, even while such thought remains inescapably mediated by subjectivity, is enough, for Adorno, to form the predicate of critical agency. Adorno calls the condition for this glimpse Erschütterung - a 'tremor' - which 'signals the breaking through of objectivity into subjective consciousness' at the point in which the subjective response is at its most intense; such a tremor, however, is illusory: 'in its immediacy tremor senses the existence of a potential that pretends it is real' (Adorno Aesthetic 348). What Adorno outlines is therefore not a transcendent theory, but a theory in which the illusory power of the tremor gestures towards the non-identical.

Aura is thus useful here because it converges on the same axis as those Benjaminian-Adornian terms discussed in the previous chapter, and extends their application to a novel in which antiaestheticism is combined with a theory of the autonomous art object. As Kaufman's essay demonstrates, aura is important to consider when exploring Adorno's aesthetic theories, for it is partly through his idea of auratic art - particularly as it is expressed in the lyric mode - that his negative dialectics becomes increasingly coherent as a theoretical framework. As I have argued, in Infinite Jest there is a tension between the machinations of form the novel performs, and the anti-aesthetic sensibility it contains. In the following section, I want to expand this point, and suggest that while Infinite Jest approaches the kind of auratic distance (and critical agency) Adorno finds in the lyric, this is ultimately negated by the novel's insistence upon an essentialist, transcendental schema, in which art objects are, phenomenologically speaking, wholly accessible to the subject and thus capable of providing not just a 'glimpse' beyond subjectivity, but an escape from subjectivity itself.

This central problem of Infinite Jest's aesthetics is evident towards the end of Joelle's reflection on Incandenza's films. After dismissing much of the oeuvre, Joelle turns her attention to the film "Pre-Nuptial Agreement of Heaven and Hell", the story of an 'alcoholic sandwich-bag salesman' that concludes with a '240-second motionless low-angle shot' of The Ecstasy of St 
Theresa (742). The entire film is shot from the salesman's point of view; the final shot's significance, for Joelle, is thus predicated on this first-person perspective:

The statue, the sensuous presence of the thing, let the alcoholic sandwich-bag salesman escape himself, his tiresome ubiquitous involuted head, she saw, was the thing. The four-minute still shot maybe wasn't just a heavy-art gesture or audience-hostile herring. Freedom from one's own head, one's inescapable P.O.V. - Joelle started to see here, oblique to the point of being hidden, an emotional thrust, since the mediated transcendence of self was just what the apparently decadent statue of the orgasmic nun claimed for itself as subject. [...] [T] he film's climactic statue's stasis...presented the self-forgetting of alcohol as inferior to that of religion/art. (742)

Though the term 'mediated transcendence of self' seemingly recalls Adorno, Joelle's reading clearly indicates that the art object is circumscribed by this function; that is, the purpose of the statue in the film is simply to provoke the transcendence of the spectator, just as the static shot of it is supposed to produce the same effect for the film's audience. The art object - 'the thing' - is not opaque but wholly available to the spectator; the statue's 'sensuous presence' is, as I have argued, conceived as autonomous and static, and thus representative of the real or actual in both the internal and external subject-object relations of the novel. Further, that the final sentence describes a hierarchy of objects through which to achieve such transcendence is important. Throughout Infinite Jest, characters are engaged in the pursuit of 'self-forgetting' most obviously through numerous drug and alcohol addictions, but just as persuasively through television and "Infinite Jest" itself. ${ }^{22}$ Until this point, this pursuit is almost wholly negatively framed, yet here Joelle identifies the idea of transcendence as the 'moral thesis' of Incandenza's work. As described previously, Incandenza's film work is almost universally disparaged by the novel's other characters. It stands to reason, then, that the moral thesis of Incandenza's work should be taken in the same light: that is, it represents the opposite of what the novel, itself an art object, asks of its reader. There certainly seems to be a disparity between this pursuit of self-forgetting and the 'Living in the Present' cliché espoused by Alcoholics Anonymous. The presentation of the transcendent schema here, focalised as it is through Joelle, neither supports nor negates Incandenza's 'moral thesis'. Yet whether the schema described here was intended to be viewed in opposition to the novel's main thesis is irrelevant. Because of how the statue is situated within the novel, it becomes clear that its claim to actuality is consistent with, rather than in opposition to, the way in which AA clichés

\footnotetext{
${ }^{22}$ The most clear-cut example of television addiction outside of the special case of "Infinite Jest" comes in the story of Steeply's father, who becomes 'consumed' by the television series $M^{*} A^{*} S^{*} H$ (638-648). Steeply describes his father as eventually appearing, '[p]ulled apart in different directions... [a]s if he were stuck wondering. As if there was something he'd forgotten' (647). Throughout the novel there is an important connection drawn between addiction, the forgetting of self, and stasis.
} 
also delimit an accessible actual. The text itself mirrors the essentialist, transcendental schema of "Pre-Nuptial Agreement" through its embedded art objects, and through the employment of a narrative style that is non-linear and assumes an outside perspective.

This chapter's reading of the novel is in part a response to the thread of Wallace criticism that argues the novel is in fact dialogic in nature. Adam Kelly suggests that in Wallace we find, following Mikhail Bakhtin, 'a dialogic context in which both sides of the argument can be offered to the reader, without a clear authorial conclusion drawn' (Kelly Dialogue 275). ${ }^{23}$ Kelly's point that there is no clear authorial conclusion to be drawn from Infinite Jest is based on the various dialogues of 'ideas' between characters in the novel, particularly the recurrent MaratheSteeply dialogue. In this instance, his assertion perhaps holds true; as he states, both Marathe's and Steeply's sides of the argument read persuasively (Kelly Dialogue 275). Yet this argument seems to ignore those places in the novel - some of which I have detailed in this chapter - in which the text itself quite clearly points to which 'side' of the various arguments made is valued more highly. That a novel might remain in a dialogic state while also having a fundamentally essentialist metaphysical basis is incoherent. This also negates Kelly's claim that 'there is therefore no bottom line in Wallace's novels, no master discourse ... there are instead a plurality of ways to approach the problem Wallace is addressing' (Kelly Dialogue 280). Yet the treatment of art objects within the novel directly supports the assertion that there is an outside text to Infinite Jest.

In Infinite Jest Wallace works to establish an accessible 'actual' - aligned throughout with the Adornian anti-aesthetic - which while not necessarily physical or material is always invariant; that is, the actual as a category in Infinite Jest is essentialist, assuming the possibility of an ahistorical, non-contextually-dependent subject-object relation. This, importantly, reflects Wallace's own statement on the idea of the real:

\footnotetext{
${ }^{23}$ See also the echo of a similar sentiment in Tim Personn, "The Dave Show". Personn states:

If it was impossible, however, to articulate ethical propositions in a straightforward manner, Wallace reasoned, he could still try to approach them indirectly. Indeed, Wallace's solution to the problem of addressing Wittgenstein's ineffable was dialectical. His texts, above all Infinite Jest, contained their own criticism, calling into question their own assumptions about metaphysical certainties. They spiraled upwards in ever-rising doubt, causing vertigo in readers who tried to sort out which attitude was superior: Hal Incandenza's ennui or his brother Mario's sentimental antics? Sociologist Geoffrey Day's sarcasm or ex-addict Don Gately's infantilization? With no authorial commentary to guide them, Wallace's readers were deflected back into their own value judgments. (Personn 2011)
}

My point, here, is that such criticism takes the formal and structural features of Infinite Jest - in particular the number of sections devoted to various characters - and ignores the consistencies and discrepancies in their rendering. For instance, if there is no recourse to 'authorial commentary' in Infinite Jest, how can the use of irony with regard to Incandenza's filmography be accounted for? 
Everyone is extremely conscious of manipulating how they come off in the media; they want to structure what they say so that the reader or audience will interpret it in the way that is most favorable to them. What's interesting to me is that this isn't all that new. This was the project of the Sophists in Athens, and this is what Socrates and Plato thought was so completely evil. The Sophists had this idea: Forget this idea of what's true or not-what you want to do is rhetoric; you want to be able to persuade the audience and have the audience think you're smart and cool. And Socrates and Plato, basically their whole idea is, "Bullshit. There is such a thing as truth, and it's not all just how to say what you say so that you get a good job or get laid, or whatever it is people think they want." (Wallace 1999)

In his dismissal of 'rhetoric', Wallace again posits a clear-cut distinction between actual and virtual. His own rhetoric here is important: consistent with Infinite Jest, Wallace expounds an anti-formalist or anti-aesthetic position, the 'truth' of which is supported by the supposed lack of attention to form in its utterance. This is of course nonsensical: the rhetorical strategy of 'dumbing down' Wallace uses to reinforce his point is commonplace. In light of the above quote, it is important to point here to the extensive critical and cultural attention paid to Wallace himself as harbinger of a shift towards what has variously been called 'postpostmodernism', 'metamodernism' or the 'New Sincerity'. Such accounts lie outside the scope of this chapter (and thesis), but it is important to bear in mind the correlation between the conception of aesthetic sincerity, authenticity or 'goodness' in Infinite Jest, and Wallace's oftcited own views on the matter. ${ }^{24}$

Through exploring the descriptions of art objects in the novel, it becomes apparent that the 'truth' of which Wallace speaks - the 'actual' of Infinite Jest - has no inverse within the novel: while the 'virtual' is gestured towards in Incandenza's filmography, particularly in 'Infinite Jest" itself, it is never included as a viable aspect of the subject's encounter with the world. Without the negative definition of the virtual, however, the 'actual' comes to seem increasingly arbitrary and incoherent. Through this lack of the virtual the novel is circumscribed. In the attention to the pursuit of the 'actual', and the dismissal of those aspects of aesthetic relations that fall under the category of the 'virtual', Infinite Jest, despite its often recursive nature, avoids reflection on itself as an aesthetic object, as both a physical object in the world and a 'virtual' object.

To return, briefly, to the description of "Pre-Nuptial Agreement of Heaven and Hell", Bernini's statue again provides a useful model for the kind of subject-(aesthetic)object

\footnotetext{
24 Of particular interest here are Wallace's own "E Unibus Pluram" essay, and the interview with Larry McCaffery that accompanied its original publication. In terms of criticism, see Adam Kelly's "David Foster Wallace and the New Sincerity in American Fiction", wherein the concept of 'sincerity' in Wallace's oeuvre is interlocuted through reference to Lionel Trilling and Jacques Derrida.
} 
relations the novel delineates. Art objects found in fiction have all the qualities - and associated possibilities - of the virtual; that is, they are not tethered to the material world through anything other than the actual, printed text on the page. Yet in Infinite Jest the possibilities of such virtuality are never explored; art objects in the novel remain statue-like: fixed, invariant, and attached to a metaphysical schema that is itself non-productive. If constellatory thought holds the possibility of critical agency through allowing the subject a glimpse of the non-identical, such a model is also based on movement and change, on the historical and material permeability of the object. As Alison Stone describes:

...it seems that constellations can never exhaustively grasp an object because of the nature of objects, specifically the fact that their histories - which make them the particular objects they are - are unfinished, ever ongoing. Concepts are incomplete because their objects are incomplete, embroiled in processes such that many aspects of their past histories are simply not available to be grasped. (Stone 60)

Infinite Jest is therefore a text that appears to approach the constellatory mode: its lack of final narrative coherence and intermittent use of the philosophical dialogue might be read as formal gestures towards the impossibility of ever fully accessing the object. Yet through the object relations depicted within the text, and in a wider sense the text's own relation to the reader and to the world, it becomes clear that the position Infinite Jest occupies is steadfastly noncritical, and, finally, contradictory. Adorno's model of negation is not necessarily the standard by which all texts must be judged. Infinite Jest, however, is what might be called a novel of ideas; because of this, any interlocution of the novel must take into account not only those ideas the novel engages with explicitly - the adumbration of which has become the primary mode of most Wallace criticism - but how, and on what basis, such philosophising takes place. The issue, therefore, is not that Infinite Jest fails as a novel, but how, through taking the novel as not just a representation of the world but a mode of thought in itself, the text's philosophical critique is negated by the form such critique takes. 


\section{Conclusion}

Like a wave breaking on a rock, giving up Its shape in a gesture which expresses that shape.

- John Ashbery, "Self-Portrait in a Convex Mirror"

What I hope to have shown in looking at Lerner and Wallace in tandem is how ekphrasis and embedded art objects reflect the larger problematic of the novel mode. Both novels are overwhelmingly concerned with the question of reference - of how text can relate to the world. The representation of the art object thus offers a framework for examining this concern; due to the nature of ekphrasis, however, such typically 'postmodern' questions can be rephrased in relation to the aesthetic tradition in order to give a more nuanced account of how each novel functions. I want now to make clear what I see as the central difference between each novel's figuring of the subject-world relation, and, perhaps more importantly, extrapolate from this difference how I understand ekphrasis and the embedded art object as relating to the project of literary criticism in general. This latter claim might sound grand; what I hope to achieve here, however, is not some new theoretical paradigm - the small pool of texts that actually include the ekphrastic mode is, of course, essentially limiting - but instead to provide an example of how, through moving the questioning of the embedded art object away from representational adequacy and towards a wider conception of aesthetics, it might be possible to arrive at productive - and original - ways in which to consider the literary text. ${ }^{25}$

The central event of Leaving the Atocha Station is the bombing of the Atocha station in Madrid: it is what precipitates the demonstrations in which Adam reluctantly takes part, and therefore

\footnotetext{
${ }^{25}$ Contemporary novels which employ the ekphrastic mode are few and far between, but exciting examples do exist: during the writing of this thesis Rachel Kushner's The Flamethrowers was published, a novel which - had it been available earlier would surely have had a larger role in the present piece. Suffice to say, the novel is concerned with many of the questions I raise here, and is one I hope to incorporate into any further revisions of this project. Lerner's review of The Flamethrowers is worth noting: Lerner sees in the novel a dichotomy between Fried and Peter Bürger's perspectives on the relation of art to life, concluding that 'fiction is peculiarly suited to tracking the dispersion of art into performance' (Lerner "A Trace of a Trace").
} 
catalyses much of the action in the novel's third act. What is particularly important, however, is that the discourse around this event is explicitly concerned with the relation of an event or thing to its representation; that is, the relation of actual to virtual, art to life. This is a concern throughout the novel, but in this case it takes on a particular urgency: if the actual is characterised by action-orientation, an event that occupies a single moment in time and yet has such extensive repercussions seems to make obvious the distinction between actual and virtual. In the novel this idea is subverted, however, by Adam's reaction to the bombings: excepting a half-hearted attempt to give blood, Adam mostly withdraws from the actual experience of the bombings' aftermath and instead reads articles online that, as he states, 'describ[e] the helicopters I could hear above me' (118). What becomes obvious here is the ambivalent nature of the relationship of subject and object when the distinction between actual and virtual is blurred. Throughout this thesis, I have emphasised the productive potential of the dialectical tension on which the novel is based. Yet it is also important to note that the impossibility of a wholly accessible object also opens up the possibility for manipulation: if a subject-object encounter consists of the actual existence of the object and the virtual experience of the subject, events such as the Madrid bombings - or to perhaps a less obvious extent the drowning of the girl in Mexico - make clear the limitations of such a schema as a universally ethical system. Leaving the Atocha Station ends with a seemingly positive celebration of the actual-virtual dialectic, yet this is undermined by the paragraphs which immediately precede it. Adam is prompted by seeing Teresa to state that '[w]e didn't know many working people', in reference to an earlier conversation in which, upon being asked if she knew anyone who had died in the bombings, Teresa 'said many of the dead were immigrants...that it was a crime against working people and she didn't know many working people' $(180,126)$. In the narrative present of the novel's conclusion, Adam then asks a friend if he can name 'a famous living poet'. The friend cannot; the line between 'virtual' art and 'actual' life seems to again be emphasised, or at least acknowledged, in the lack of connection between the space Adam and Teresa inhabit as poets and artists and the lives of other, less privileged characters - or 'working people' - who do not appear in the novel. The implication is that through emphasising the indiscernibility of actual and virtual an excuse can be made for disengagement. While the distinction between actual and virtual is broken down throughout the novel, there is a certain sense that this model is one of compromise: the productive possibility of 'exacerbating contradictions' and the 'pure potentiality' of the virtual in itself do not result in change in a political, social or even ethical sense, but is rather a condition or mode of being in which such changes have the potential to occur. 
This is consistent with how art is conceptualised throughout the novel, as Adam constantly emphasises the impotency of art as an agent for action. He is particularly fond of repeating Auden's famous line that 'poetry makes nothing happen', but - just as the original line is clarified by the suggestion that poetry rather 'survives... is a way of happening, a mouth' Adam's lack of faith in art's relation to the world is complicated by his own status as a poet (Auden 36, 41). Adam inhabits the contradictory space of writing a political poem while proclaiming the inefficacy of poetry based on its inherent separation from the actual world of war and bombs. Of course, the novel itself also inhabits this position: it exhibits a tension between acknowledging the impossibility of unmediated access to the 'actual' when the actual is construed as an object, while simultaneously suggesting that the novel is itself a mode of being, an event no less actual or virtual than any other. Adam's insistence that he 'would never write a novel' is therefore not just an ironic nod at the reader. It is in the inherent impossibility of thought to be coeval with its object that the novel's mode of being is found. In this sense, Lerner's novel exhibits a sensibility much like Adorno's negatively charged aura; like the lyric, Leaving the Atocha Station is auratic in that the text makes clear the limits of its form, while suggesting through content that critical agency can be found in this lack. The story event of the Madrid bombings therefore catalyses much of the narrative's movement, but it fails to change in any meaningful way the relationship between actual and virtual configured in the novel up to the point of its occurrence. To do so would be disingenuous because while the bombings exist extra-textually, within the novel they are no less actual or virtual than any other object of reference. Leaving the Atocha Station includes important historical events but is not in any direct sense about them; rather, Lerner refers to such events to reiterate a point that could theoretically be made about any event but is made particularly apparent in the case of those which carry enormous weight outside of the novel.

It is possible to see in this position echoes of Fredric Jameson: as described by Bewes, Jameson understands postmodern cultural production as 'a form which has reached its own limits, which is determined by necessary failure, and which resolves the supposed antinomies of modernity simply by inhabiting them as their "cultural logic" (Bewes Event 18). Bewes argues, however, that such theories are limited by a periodising impulse that recognises postmodern literature as 'a form that incarnates failure, inherent impossibility' through understanding formal features - such as double-coding or metafiction - only in relation to a more general postmodern aesthetic characterised by depthlessness, banality, and nihilism (Bewes Event 7). Such forms of criticism neglect to discuss the novel form itself, and thus ignore those aspects of a text that subvert this generalisation. Turning to Lyotard, Bewes 
suggests that rather than leading to negativity, nihilism and flatness, the postmodern literary text is in fact animated by its own impossibility, by 'the task of making a presentation in a situation where presentation has become impossible' (Bewes Event 7). While Bewes does not refer to either theorist, it is not difficult to trace such remarks to the same strain of critical theory as Benjamin and Adorno. Like these theorists, Bewes is suggesting that there exists a point at which the art object is itself an event, and that '[i]n this moment the ethical substance of the text exceeds mere "ethical" commentary, abolishing the ethical simultaneously with its inauguration as the spiritual actuality of the material world' (Bewes Event 14). ${ }^{26}$ To this ethics predicated on 'spiritual actuality', compare Adorno's own ethical configuration, described in the previous chapter, wherein critical agency - a glimpse of alterity - is found through auratic distance. In both cases the ethical or critical response is a material and sensuous rather than wholly intellectual experience; the ethical 'comes into being only at the moment of its disappearance into sensation' (Bewes Event 18). In this sense, Bewes' argument is important here as it suggests a distinction between accounts of the postmodern which, through their periodising impulse, in fact ignore the particulars of the individual novel's relation to the world, and a history of critical theory that instead emphasises attention to subject-object relations rather than questioning only representational adequacy.

To return to the texts under discussion, then: Adam's statement that he 'would never write a novel' indicates not just a concern with art's ability to represent life, but also with the possibility of the novel to exist as an event in itself, as a 'way of happening'. This coevality of experience is gestured towards within the novel, when Adam reads Tolstoy on the train to Granada:

I flipped through the Tolstoy for a half-remembered passage about a train, but couldn't find it. It didn't matter; every sentence, regardless of its subject, became mimetic of the action of the train, and the train mimetic of the sentence, and I felt suddenly coeval with its syntax. Because the sentences of Tolstoy, or rather Constance Garnett's translations of Tolstoy, were in perfect harmony with the motion of the Talgo, real time and the time of prose began to merge, and reading, instead of removing me from the world, intensified my experience of the present. (89)

\footnotetext{
26 The exact nature of such an 'event' is not delineated by Bewes in this essay, though in other work on the same topic he suggests that the concept as he uses it derives from a nexus of Deleuze, Lyotard and Alain Badiou (Bewes Escape n.1,47). The inclusion of Badiou here does not clarify things exactly; Badiou himself seems uncertain on what constitutes an event, despite it forming the cornerstone of much of his mathematically-based ontology. Badiou's philosophy is immensely complex and regrettably falls outside of the scope of this thesis; it is enough to refer here to two points: his summation of the event as that which 'compels us to decide a new way of being' and his description of the event as a supplement - i.e. an excess - existing outside of ontology (Badiou Ethics 41).
} 
The idea of translation is important here: Adam is aware that his experience of Tolstoy is already twice-removed, and so it is not through accessing the text itself that his experience of the present is intensified. Unlike Lukács's 'happy ages', here an awareness of mediation itself becomes part of sensuous experience. For Adam, such an experience is reminiscent of reading John Ashbery. Adam suggests that in Ashbery 'one could experience the texture of time as it passed, a shadow train, life's white machine'; that the lines reproduce the propulsion of thought without the corresponding particularity of thoughts or stable referents (90). ${ }^{27}$ The effect is that mediation is experienced immediately: 'as though the actual Ashbery poem were concealed from you, written on the other side of a mirrored surface, and you saw only the reflection of your reading', thereby creating a kind of presence in which the 'virtual possibilities of poetry' remain intact $(91) .{ }^{28}$ What Adam locates in Ashbery's work is that which Adorno and Benjamin figured in the lyric mode - that is, a profundity derived from absence. The absence - or loss - of an accessible actual - a stable referent, in the terms Lerner employs in relation to Ashbery - is the same condition Lukács considers to be the world of the novel; the experience of subjective mediation simply is experience. In this sense, Ashbery's brief appearance in Leaving the Atocha Station is important: it offers a concrete example of what the coevality of thought and experience Adam experiences when reading Tolstoy might look like outside of the novel. This seems, to my mind, to be an experience quite different from the idea of postmodern impossibility or metatextuality as conceptualised by Jameson and (many) others: as in the reading of Leaving the Atocha Station I have offered thus far, what Adam finds in Ashbery is instead the negative determination of the lyric mode.

In Leaving the Atocha Station, the tension between actual and virtual is the function of an ontology which posits the object as fundamentally inscrutable. Infinite Jest instead represents a textual world that is less obviously 'realist' than Lerner's while also appearing to emphasise its own objecthood - the novel's size and the extent of its footnotes making the reader constantly aware of its physicality. ${ }^{29}$ Yet Infinite Jest does all this while also remaining committed to an

\footnotetext{
27 Adam's reading of Ashbery is actually Lerner's: Lerner published an essay prior to the publication of Leaving the Atocha Station, "The Future Continuous: Ashbery's Lyric Mediacy", in which he argues that Ashbery makes us 'attend to our attention' and experience our own experience of the temporality of reading (Lerner 209). Lerner also makes the point that in Ashbery what appears to be an impatience with criticism is in fact exasperation with its redundancy when his poetry is itself 'already a kind of secondary text' (Lerner Ashbery 209). Ashbery's relationship to criticism is therefore, like Lerner's, far more complex than a simple equation of intellectualism with abstraction.

28 Though not referenced in the novel or Lerner's essay, John Bayley's essay on Ashbery suggests a similar reading: Bayley refers to Ashbery's work as 'ghost' or 'shadow' poetry because it is based upon the premise that 'we can never see the object or the person as it really is, never quite know what we see or see what we know' (Bayley 35).

29 Wallace's aesthetic has been compared to Incandenza's own 'radical realism', presenting the 'unfiltered babble of the peripheral crowd' (LeClair 32). Yet despite the multitude of narrative voices in the novel, there still remain instances - such as the example of the tense shift to the gnomic present detailed above - in which this appearance of messiness is shown still to be subject to the novel's central aesthetic and ontological organising principles.
} 
accessible real that is inaccessible through language. The project of Infinite Jest to an extent thus undermines itself. Rather than accepting the limitations of the novel mode as a way of thought, Infinite Jest seems to impose itself on the reader as a material object - as part of the real, actual world. As in the treatment of The Ecstasy of St Theresa, Wallace accepts physical presence as the absolute against which all other experience is judged.

That each novel is predicated on such different aesthetic and philosophical schemata might not seem problematic in itself. Yet such differences have implications for the critic; the subject-object relations demonstrate two quite different conceptions of how the world is to be accounted for in thought. As discussed previously, in Leaving the Atocha Station critical theory is incorporated into the narrative discourse seamlessly: Adam quotes from Lukács, Adorno and others without citation. This is in direct contrast with Infinite Jest, wherein 'theory' in general is derided and made strange: theoretical discourse is represented as excessively detailed (the filmography) or simply ridiculous (Geoffrey Day). The problem with the latter approach, however, is that it ignores the historical moment of its writing, in which theoretical discourse is as much a part of experience as the physical or corporeal. Such a position is impossible to successfully maintain within the constructed object of the literary text; it implies a hierarchical model of referential adequacy which is eventually untenable. There is a comparison to be drawn here to what Jacques Rancière identifies as the problem with Fried's work: the latter's anti-theatre position is paradoxical because it is derived directly from the theatre, being 'the theory of a dramatic action that would pretend to be invisible, to be viewed by no audience, to be nothing but life in its pure similarity to itself (Rancière 88). As Rancière points out, however, this leads to the question: 'what need would life in its pure similarity, life 'not looked at', not made into a spectacle, have of speaking?' (Rancière 88). Infinite Jest similarly suggests that the actual world cannot be accessed or represented in text, and yet it is a textual object itself. Its relationship to the actual is one of mediation, and this mediation is highlighted within the novel. Yet there is always the implication that this mediation is not essential, that subjectivity can be transcended through pure experience of the actual.

What Lerner in Leaving the Atocha Station attempts to evoke is, in contrast, the texture of experience itself. If, as Deleuze and Bergson suggest, we experience time as duration, then all experience must be essentially poised between the actual and virtual - between action and thought. It makes sense, then, that when Adam states that he will 'never write a novel' it is because narrative - and thought itself - is unable to capture the sensual experience of 
duration; though narrative by necessity moves forwards, it is based around individual events and can thus only represent the actual:

These periods of rain or periods between rains in which I was smoking and reading Tolstoy would be, I knew, impossible to narrate, and that impossibility entered the experience... Not the little lyric miracles and luminous branching injuries, but the other thing, whatever it was, was life, and was falsified by any way of talking or writing or thinking that emphasized sharply localized occurrences in time. (64)

Note that here Adam does not differentiate between 'writing and thinking'. Rather than positing a particular failure of the literary to capture the object, what is suggested here is the impossibility of all modes of thought to capture duration. It is for this reason that studies of ekphrasis that focus solely on the question of reference are limiting: what Leaving the Atocha Station shows is instead how art objects act as something like microcosms of a larger relation between subject and world that goes beyond the capacity for representation. As Lukács states in The Theory of the Novel, the division upon which the novel form is based (and therefore reflects) is between 'the conventionality of the objective world and the interiority of the subjective one' (Lukács Novel 70). While both Leaving the Atocha Station and Infinite Jest are concerned with whether the experience of language can be coeval with the sensual experience of the real, the essential difference is that while Wallace posits a real based on physicality and presence, and therefore emphasises the inability of language to have the same effect, Lerner is concerned with the idea that text itself is a sensual experience - not solely in a physical or material sense, though Leaving the Atocha Station certainly destabilises the boundary between materiality and language through the use of the embedded photographs - but in the sense that its reading can be an event in itself. Lerner thus attempts not just to represent the actual but to provide an experience that is in and of itself equal to non-textual experience.

As stated, such perspectives have implications for the act of criticism itself. A large part of why Michael Fried is against 'literalist' art is that it 'seeks to declare and occupy a positionone that can be formulated in words and in fact has been so formulated by some of its leading practitioners' (Fried 148). Fried is referring in particular to the writings of Donald Judd, whose "Specific Objects" clearly delineates the minimalist ethos, and from which Fried quotes throughout his essay (Judd 181). Fried implies that it should not be possible to articulate the 'position' of art; his criticism of Judd et al is based on a clear definition, sustained throughout the essay, between art that has such a position (and which is therefore implicitly nonautonomous; it is enmeshed in the situation of its inception) and art that does not (i.e. modernist, autonomous art). That Fried figures this separation through the ability for art's 
position to be articulated - for the object to be translated into thought - is central. Wallace and Fried share a suspicion of this articulation, not because of a characteristically 'postmodern' sensibility that suggests there is no outside real to be articulated, but because a position that can be 'formulated in words' - that is, in criticism - suggests that the object can be translated into thought, a suggestion which would undermine the entirety of the hierarchical metaphysical system upon which their thought is predicated. While Lerner's text also suggests that the object is inaccessible, the crucial difference is that in Leaving the Atocha Station this impossibility is applied to all thought. Because there is no single static experience of the object - because experience is duration, and duration includes both the actual and the virtual - it would be impossible to simulate such an experience in text. What Lerner is attuned to, however, is the ability for the text to momentarily generate the full complexity of this experience, crucially including the feeling of impossibility or inaccessibility that characterises our experience of the objective world. An essential part of this experience is the inclusion of critical discourse. To posit, as Wallace does, a gulf between language and experience that is forever unbridgeable is to deny the possibility that language might reflect or comment on the present moment, to section theory off from any experience of the 'actual' and to suggest that while an object can be experienced in full, can prompt transcendental experience through physicality, this experience is in some way separate and distinct from all others - and from the virtual.

The work of the virtual - that is, intellectual work - is equated in Wallace to disengagement from the real, to solipsism and thus to a failure of empathy. In the model of the AA programme, thought is itself evacuated of its virtual potential; through the anti-intellectual gesture of reiterating clichés and bromides, Wallace suggests that ahistorical, non-reflective thought is the kind that produces change. Those who submit to the AA programme become better people, but because the novel is based around the negative capacity of thought - the desperation and recursive thinking typical of addicts - there is a blanket assumption that any thought that is not action-oriented - i.e. the virtual - results in despair. The kinds of sentimentality and pathos Wallace employs are therefore understandable: in emphasising the truth value of such received statements, however, Wallace suggests a schema in which the potential for critical agency is suppressed.

What Wallace finally suggests, then, is a schema in which the actual and virtual are not meaningfully linked and in which the art object is therefore essentially separate from life. The text of Infinite Jest leaves us in no doubt that Wallace's project was based on articulating a 
system of ethics, of suggesting that through becoming aware of mediation one can somehow fight through and achieve unadulterated access to the actual, and become more empathetic and aware as a result. Yet in doing so, Wallace fails to acknowledge the place that mediation has in developing this and any conception of ethics. If we follow Adam's reading of Ashbery, any contemplation of the present moment must incorporate the act of reflection itself. A lack of theory therefore means a lack of examination of the present world at hand; thus in Wallace we find an ahistorical concept of ethics that undermines itself by drawing a firm line between the world and our ability to think it. In contrast, in Lerner we can see a concern with, if not an attempt at, the collapsing of art into experience. Leaving the Atocha Station is far less concerned with received notions of ethical responsibility or even spirituality than Infinite Jest. Rather, the schema upon which it is predicated gestures towards the conditions necessary for any change - collective or individual - to occur. Lerner's idealist vision at the novel's close is tempered by what precedes it; the limitations of the various critical axes it draws from are therefore made clear. What both novels offer, then, is a compromised response to the division between subjective and objective worlds Lukács identifies: as ekphrasis suggests, perhaps the novel as a mode of thought is best suited to expressing its own limitation. 


\section{Works Cited}

Adorno, Theodor W. Aesthetic Theory. Trans. C. Lenhardt. London: Routledge \& Kegan Paul, 1984. Print

---. Minima Moralia: Reflections from Damaged Life. Trans. E.F.N. Jephcott. London: NLB, 1974. Print.

---. Negative Dialectics. Trans. E.B. Ashton. New York: The Seabury Press, 1973. Print.

Ashbery, John. Self-Portrait in a Convex Mirror. New York: Viking Press, 1975. Print.

Auden, W.H. "In Memory of W.B. Yeats". Selected Poems. Ed. Edward Mendelson. New York: Vintage, 1979. Print.

Badiou, Alain. Ethics: An Essay on the Understanding of Evil. Trans. Peter Hallward. London; New York: Verso, 2001. Print.

Bayley, John. Selected Essays. Cambridge: Cambridge University Press, 1984. Print.

Benjamin, Walter. Illuminations. 1968. New York, NY: Schocken Books, 2007. Print.

Bergson, Henri. Time and Free Will: An Essay on the Data of Immediate Consciousness. Trans. F.L. Pogson. New York: Dover Publications, 2001. Print.

Bewes, Timothy. "How to Escape from Literature? Lukács, Cinema and The Theory of the Novel'. George Lukács: The Fundamental Dissonance of Existence. Eds. Timothy Bewes and Timothy Hall. London: Continuum International Publishing, 2011. Print.

---. "The Novel as an Absence: Lukács and the Event of Postmodern Fiction". Novel : $A$ Forum on Fiction 38.1 (2004): 5-20. Print

Bloch, Ernst, et al. Aesthetics and Politics. Trans. Ed. Ronald Taylor. London: NLB, 1977. Print.

Brown, Bill. “Thing Theory”. Things. Ed. Bill Brown. Chicago, IL: The University of Chicago Press, 2004. Print. 
Bruhn, Siglind. Musical Ekphrasis: Composers Responding to Poetry and Painting. Hillsdale: Pendragon, 2000. Print.

Burn, Stephen. Review of Consider David Foster Wallace, ed. David Hering. Modernism/modernity 18.2 (2011): 465-468. Print.

---. Conversations with David Foster Wallace. Jackson, MS: University Press of Mississippi, 2012. Print.

---. David Foster Wallace's Infinite Jest: A Reader's Guide. London: Continuum Contemporaries, 2003. Print.

Bürger, Peter. Theory of the Avant-Garde. Trans. Michael Shaw. Minneapolis: University of Minnesota Press, 1984. Print.

Cohen, Samuel, and Lee Konstantinou, eds. The Legacy of David Foster W allace. Iowa: University of Iowa Press, 2012. Print.

Currie, Mark. Postmodern Narrative Theory. 2nd ed. Basingstoke: Palgrave Macmillan, 2011. Print.

Deleuze, Gilles. Cinema 2: The Time-Image. Trans. Hugh Tomlinson and Robert Galeta. Minneapolis, MN: University of Minnesota Press, 1989. Print.

Deleuze, Gilles and Félix Guattari. A Thousand Plateaus. Trans. Brian Massumi. 1987. London: Continuum, 2004. Print.

Eve, Martin Paul. "Thomas Pynchon, David Foster Wallace and the Problems of 'Metamodernism': Post-millenial Post-Postmodernism?’. C21 Literature: Jounral of 21stcentury Writings 1.1 (2012): 7-25.

Franzen. Jonathan. Farther Away. New York: Farrar, Straus and Giroux, 2012. Print.

Fried, Michael. Art and Objecthood: Essays and Reviews. Chicago, IL: The University of Chicago Press, 1998. Print.

Green, Karen. Bough Down. Los Angeles: Siglio, 2013. Print.

Hall, Timothy. "Adorno's Aesthetic Theory and Lukács's Theory of the Novel”. Adorno and Literature. David Cunningham and Nigel Mapp (eds.). London: Continuum, 2006. Print.

Hansen, Miriam Bratu. “Benjamin’s Aura”. Critical Inquiry 34 (2008): 336-375. Print.

Heffernan, James. Museum of Words: The Poetics of Ekphrasis from Homer to Ashbery. Chicago, IL: University of Chicago Press, 1993. Print. 
Hering, David. "Editor's Preface". Consider David Foster Wallace. Ed. David Hering. Los Angeles: Sideshow Media Group, 2010. Print.

Jackson, Robert. "The Anxiousness of Objects and Artworks: Michael Fried, Object Oriented Ontology and Aesthetic Absorption”. Speculations 2 (2011): 135-168.

Jarvis, Simon. Adorno: A Critical Introduction. New York, NY: Routledge, 1998. Print.

Jay, Martin. Adorno. Cambridge, MA: Harvard University Press, 1984. Print.

Judd, Donald. Complete Writings 1959-1975: gallery reviews, book reviews, articles, letters to the editor, reports, statements, complaints. Halifax: The Press of the Nova Scotia College of Art and Design, 2005. Print.

Karnicky, Jeffrey. Contemporary Fiction and the Ethics of Modern Culture. New York: Palgrave Macmillan, 2007. Print.

Kaufman, Robert. “Aura, Still”. Walter Benjamin and Art. Ed. Andrew Benjamin. London, UK: Continuum, 2005. 121-147. Print.

Kelly, Adam. "Development through Dialogue: David Foster Wallace and the Novel of Ideas". Studies in the Novel 44.3 (2012): 267-283.

---. "The New Sincerity in American Fiction". Consider David Foster Wallace. Los Angeles: Sideshow Media Group, 2010. Print.

LeClair, Tom. "The Prodigious Fiction of Richard Powers, William Vollmann, and David Foster Wallace”. Critique 38.1 (1996). 12-37. Print.

Krieger, Murray. Ekphrasis: The Illusion of the Natural Sign. Baltimore: The Johns Hopkins University Press, 1992. Print.

Lerner, Ben. “The Actual World”. Frieze. n.p., June-August 2013. Web. 3 September 2013.

---. “The Future Continuous: Ashbery’s Lyric Mediacy”. boundary 2 37:1 (2010): 201-213. Print.

---. Leaving the Atocha Station. Minneapolis, MN: Coffee House Press, 2011. Print.

---. The Lichtenberg Figures. Port Townsend, WA: Copper Canyon Press, 2004. Print.

---. “A Trace of a Trace”. Frieze. n.p., October 2013. Web. 15 November 2013.

Lukács, György. The Theory of the Novel. 1920. Trans. Anna Bostock. London, UK: Merlin Press, 1971. Print. 
---. "Thoughts Toward an Aesthetic of the Cinema". Trans. Janelle Blankenship. Polygraph 13 (2001): 13-18. Print.

McCaffery, Larry. "An Interview with David Foster Wallace”. The Review of Contemporary Fiction 13.2 (1993): 127-150. Print.

Max, D.T. Every Love Story is a Ghost Story. New York: Viking Press, 2012. Print.

Mitchell, W.J.T. Picture Theory. Chicago, IL: The University of Chicago Press, 1994. Print.

Personn, Tim. “The Dave Show”. Post45. n.p., 10 October 2011. Web. 3 December 2013.

Rancière, Jacques. The Future of the Image. Trans. Gregory Elliott. London: Verso, 2007. Print.

Rodowick, D.N. Gilles Deleuze's Time Machine. Durham, NC: Duke University Press, 1997. Print.

Sayers, Philip. "Representing Entertainment(s) in Infinite Jest'. Studies in the Novel 44.3 (Fll 2012): 346-363. Print.

Smith, Barbara Herrnstein. "Narrative Versions, Narrative Theories". Critical Inquiry 7.1 (1980): 213-236. Print.

Stein, Lorin. "The White Machine of Life". Review of Leaving the Atocha Station, Ben Lerner. The New York Review of Books. n.p., December 8 2011. Web. March 262013.

Stone, Alison. "Adorno and logic". Theodor Adorno: Key Concepts. Ed. Deborah Cook. Stocksfield, UK: Acumen, 2008. 47-62. Print.

Vermeulen, Timotheus and Robin van den Akker. "Notes on metamodernism". Metamodernism, 2011. Web. 15 Janurary 2014.

Wallace, David Foster. "100-word statement”. Rolling Stone 830/831 (Dec. 30, 1999 - January 6, 2000): 125. Print.

---. Both Flesh and Not. New York: Little, Brown and Company, 2012. Print

---. "E Unibus Pluram: Television and U.S. Fiction". Review of Contemporary Fiction 13.2 (1993). 151-194. Print.

---. Girl with Curious Hair. New York: WW Norton and Company, 1989. Print.

---. Infinite Jest. New York, NY: Little, Brown and Company, 1996. Print.

---. The Pale King. New York: Little, Brown and Company, 2011. Print. 
---. This Is Water: Some Thoughts, Delivered on a Significant Occasion, About Living a Compassionate Life. New York: Little, Brown and Company, 2009. Print.

Widiss, Benjamin. Obscure Invitations: The Persistence of the Author in Twentieth-Century American Literature. Stanford, CA: Stanford University Press, 2011. Print.

Wood, James. The Fun Stuff. New York: Farrar, Straus and Giroux, 2012. Print. 